\title{
Transcriptional profiling of identified neurons in leech
}

Elizabeth Heath-Heckman ${ }^{1,2^{*}}$ D, Shinja Yoo ${ }^{1}$, Christopher Winchell ${ }^{1}$, Maurizio Pellegrino ${ }^{1,3}$, James Angstadt ${ }^{4}$, Veronica B. Lammardo ${ }^{4}$, Diana Bautista ${ }^{1}$, Francisco F. De-Miguel ${ }^{5}$ and David Weisblat ${ }^{1 *}$

\begin{abstract}
Background: While leeches in the genus Hirudo have long been models for neurobiology, the molecular underpinnings of nervous system structure and function in this group remain largely unknown. To begin to bridge this gap, we performed RNASeq on pools of identified neurons of the central nervous system (CNS): sensory $T$ (touch), P (pressure) and N (nociception) neurons; neurosecretory Retzius cells; and ganglia from which these four cell types had been removed.

Results: Bioinformatic analyses identified 3565 putative genes whose expression differed significantly among the samples. These genes clustered into 9 groups which could be associated with one or more of the identified cell types. We verified predicted expression patterns through in situ hybridization on whole CNS ganglia, and found that orthologous genes were for the most part similarly expressed in a divergent leech genus, suggesting evolutionarily conserved roles for these genes. Transcriptional profiling allowed us to identify candidate phenotype-defining genes from expanded gene families. Thus, we identified one of eight hyperpolarization-activated cyclic-nucleotide gated (HCN) channels as a candidate for mediating the prominent sag current in P neurons, and found that one of five inositol triphosphate receptors (IP3Rs), representing a sub-family of IP3Rs absent from vertebrate genomes, is expressed with high specificity in T cells. We also identified one of two piezo genes, two of $\sim 65$ deg/enac genes, and one of at least 16 transient receptor potential (trp) genes as prime candidates for involvement in sensory transduction in the three distinct classes of leech mechanosensory neurons.

Conclusions: Our study defines distinct transcriptional profiles for four different neuronal types within the leech CNS, in addition to providing a second ganglionic transcriptome for the species. From these data we identified five gene families that may facilitate the sensory capabilities of these neurons, thus laying the basis for future work leveraging the strengths of the leech system to investigate the molecular processes underlying and linking mechanosensation, cell type specification, and behavior.
\end{abstract}

Keywords: Neurobiology, Sensory biology, Leech, RNASeq, Invertebrate

\footnotetext{
*Correspondence: each@msu.edu; weisblat@berkeley.edu

'Department of Molecular \& Cell Biology, University of California, Berkeley, Berkeley, CA, USA

Full list of author information is available at the end of the article
}

(c) The Author(s). 2021 Open Access This article is licensed under a Creative Commons Attribution 4.0 International License, which permits use, sharing, adaptation, distribution and reproduction in any medium or format, as long as you give appropriate credit to the original author(s) and the source, provide a link to the Creative Commons licence, and indicate if changes were made. The images or other third party material in this article are included in the article's Creative Commons licence, unless indicated otherwise in a credit line to the material. If material is not included in the article's Creative Commons licence and your intended use is not permitted by statutory regulation or exceeds the permitted use, you will need to obtain permission directly from the copyright holder. To view a copy of this licence, visit http://creativecommons.org/licenses/by/4.0/ The Creative Commons Public Domain Dedication waiver (http://creativecommons.org/publicdomain/zero/1.0/) applies to the data made available in this article, unless otherwise stated in a credit line to the data. 


\section{Background}

A major evolutionary advantage arising from multicellularity has been the possibility for species to generate "professional" cell types whose highly differentiated and more or less fixed phenotypes allow them to specialize in particular functions. The broad outlines of how this is achieved through cascading interactions of unequal cell divisions and inherited determinants, intercellular signaling, and transcriptional networks is understood, but numerous questions remain. Nowhere is this more evident than in the nervous system, where the diversity of morphologically defined cell types is further complicated by molecular and physiological distinctions [1-3]. Large scale transcriptional profiling at the single cell level (scRNAseq) is a powerful approach to this problem for complex vertebrate nervous systems, but at present this approach suffers from major limitations.

First is the trade-off between sequencing depth and the mRNA content of the starting sample. Low abundance transcripts are apt to be missing from the transcriptional profile altogether for scRNASeq, and stochastic variation in which transcripts are counted makes it hard to know which profiles mark phenotypically equivalent cells as opposed to subtle but significant sub-types. A second limitation of common scRNAseq technologies is the need to dissociate the tissue into its constituent cells as part of the procedure, with loss of spatial information regarding cell identity. While spatially resolved transcription profiling techniques are emerging [4], these approaches would be expected to reduce sensitivity to transcriptional differences even further than standard single-cell approaches.

Certain invertebrate nervous systems offer advantages in addressing these problems, just as they proved advantageous for elucidating aspects of neural mechanisms and neural circuits underlying behavior [5-7]. For example, their neurons are often larger in size than those in vertebrates--many neurons in gastropod molluscs, for example, are so large that even individual neurons can be transcriptionally profiled to a much greater depth than is possible for mammalian neurons [8]. In invertebrates, moreover, one or a few similar neurons coordinate functions that in vertebrates require hundreds or thousands of similar neurons. This together with the extensive body of previous work in certain invertebrate systems offers the ability to study individual cells with well-defined physiological properties and functions [6]. In addition, the comparative approach inherent in studying a range of invertebrate systems provides an evolutionary perspective to investigations of how neuronal phenotypes are defined at the molecular level.

Among invertebrates, leeches, primarily the medicinal leech species Hirudo medicinalis and $H$. verbana, have long been models for neurobiology. Pioneering neuroanatomical studies in the late nineteenth century [9] laid the basis for work which combines different experimental approaches to study facets of neurobiology and neurodevelopment ranging from behavior to ion channel function in life stages from the embryo to the adult [10-15].

The leech CNS comprises a ventral nerve cord of 32 segmental ganglia connected at its anterior end to a non-segmental dorsal ganglion. Twenty-one segmental ganglia innervate segments in the midbody of the animal. Anteriorly, four fused segmental ganglia constitute the ventral portion of the head-brain, connected to the non-segmental dorsal ganglion by circumesophageal nerves; seven fused segmental ganglia make up a tailbrain that innervates the posterior sucker.

In Hirudo, most segmental ganglia contain approximately 400 bilaterally paired, individually identifiable neurons distributed in a stereotyped manner. Many identified neurons including sensory neurons, motoneurons and the large neuromodulatory serotonergic Retzius neurons are conserved among different segments in each individual, among individuals within each species, and among different species. The physiological characteristics and behavioral roles are well-known for many of these neurons, including three distinct classes of mechanosensory neurons, the $\mathrm{T}$ (touch), $\mathrm{P}$ (pressure), and $\mathrm{N}$ (nociceptive) cells, whose large cell bodies can be visually identified by their size and position within the segmental ganglia (Fig. 1a).

Three bilateral pairs of $\mathrm{T}$ cells exhibit brief action potentials, each followed by a rapidly recovering afterhyperpolarization [16]. In response to gentle touch or water flow, $\mathrm{T}$ cells fire rapidly adapting bursts of action potentials. The three ipsilateral $\mathrm{T}$ cells have partially overlapping dorsal, ventral and lateral receptive fields, respectively, within the ipsilateral body wall [16, 17]. Two bilateral pairs of $\mathrm{P}$ cells exhibit somewhat slower action potentials and a marked sag potential in response to hyperpolarizing current injections [18]. Their mechanical thresholds are higher than those of $\mathrm{T}$ cells, and unlike $\mathrm{T}$ cells they give sustained responses during mechanical stimulation $[16,19-21]$. The medial and lateral cell bodies of $\mathrm{P}$ cells innervate partially overlapping dorsal and ventral receptive fields, respectively. P cells exemplify the use of population coding vectors to denote the position of stimuli $[19,20]$. The two pairs of $\mathrm{N}$ cells in each ganglion are polymodal nociceptors. In addition to exhibiting the highest threshold to mechanical stimulation of the skin, they respond to other noxious stimuli such as acid, high osmolarity, heat and capsaicin [22]. Their action potentials are followed by prominent afterhyperpolarizations [16]. In addition to overlapping receptive fields in the body wall, the $\mathrm{N}$ cells with more medial cell bodies also innervate the gut [17]; medial 


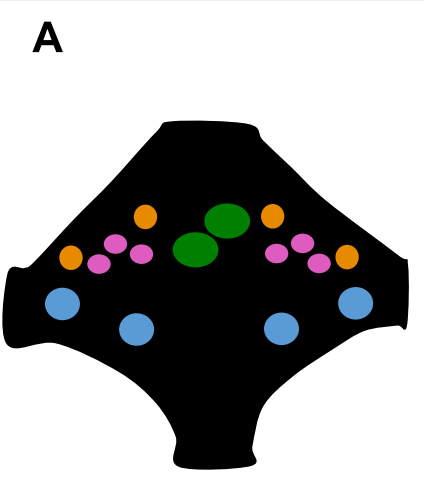

B

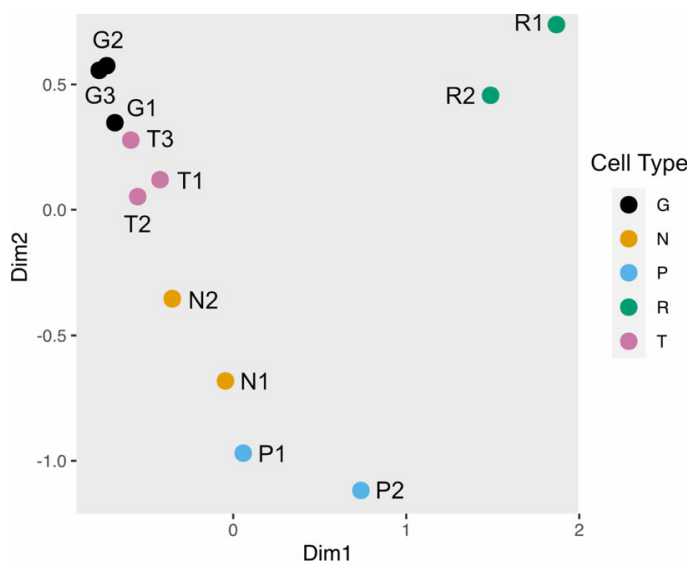

Fig. 1 Transcriptional profiles of $H$. verbana neurons and ganglia. a. Schematic of a single H. verbana segmental ganglion showing the relative positions of the neurons of interest. Each color denotes a sample evaluated in this study: Pink, T neurons (T); Blue, P neurons (P); Orange, N neurons (N), Green, Retzius Neurons (R); Dark Grey/Black, the remainder of the ganglion from which these four cell types had been removed (G). b. A Multi-Dimensional Scaling (MDS) plot showing the relatedness of the transcriptomes of each biological replicate examined in this study

and lateral $\mathrm{N}$ cells also differ in their sensitivity to capsaicin and acid [22].

In addition to the three classes of mechanosensory neurons, each ganglion contains a prominent pair of serotonergic neuromodulatory Retzius (Rz) cells [23, 24]. The electrically coupled Retzius cells have the largest cell bodies in the ganglion [25]; depending on the pattern of electrical activity they may release serotonin from nerve endings, from the axon or from the soma [26].

Identified neurons in the adult leech can be removed from ganglia individually; isolated neurons maintain their electrophysiological properties and may grow or form connections with appropriate targets [27, 28]. Thus, the leech Hirudo provides a system in which the physiological and behavioral functions of distinct, clearly defined classes of mechanosensory ( $\mathrm{T}, \mathrm{P}$ and $\mathrm{N}$ cells) and neurosecretory $(\mathrm{Rz})$ neurons can be examined in detail. Here, we have used the fact that these isolated cells robustly maintain their specific phenotypes to remove and pool neurons of specific phenotypes for RNA extraction and sequencing. For comparison, we have also profiled the transcriptome of the ganglia from which all four of these cell types had been removed. Bioinformatic analyses identified more than two thousand candidate genes whose expression differed significantly among the samples; these genes formed clusters which could be associated to varying extents with one or more of the identified cell types. We verified predicted expression patterns for selected genes through in situ hybridization (ISH) on whole leech ganglia. We also found that orthologous genes were (with certain exceptions) similarly expressed in ganglia of a rather distantly related leech, Helobdella austinensis, suggesting that the genes we assayed play evolutionarily conserved roles in this group.
In combination with genome data, transcriptional profiling also allowed us to identify candidate genes for future experiments from among expanded gene families, including specific piezo, deg/enac and trp genes as possible mechanotransducers in the $\mathrm{T}, \mathrm{P}$ and $\mathrm{N}$ neurons.

\section{Results}

Each neuronal phenotype exhibits a distinctive transcriptional profile

To determine the transcriptional profile of the four cell types, we first created a reference transcriptome by combining the RNA-Seq libraries made from pools of identified $\mathrm{T}, \mathrm{P}, \mathrm{N}$, and $\mathrm{Rz}$ neurons, and libraries made from the remainder of the ganglion after dissection of the four cell types, hereinafter referred to as ganglion-minus (Gm). Three biological replicates were prepared and sequenced for each cell/tissue type, for a total of 15 libraries (Table 1) One of the three $\mathrm{Rz}$ replicate libraries yielded a mapping rate $20 \%$ lower than any of the other 14 libraries, and was not included in this analysis. In addition, one $\mathrm{P}$ cell replicate was confirmed to be an outlier through robustPCA analysis [29] and one $\mathrm{N}$ cell replicate was a borderline outlier by robustPCA analysis and then confirmed to be an outlier by its placement on an MDS graph (Fig. S1). Both were removed from the subsequent analyses.

We processed and assembled the resultant reads with Trinity [30] to obtain a transcriptome containing 113, 388 "isoforms", sequences that may represent variants due to processes such as differential splicing. These isoforms were then grouped into 51,875 "genes" (Supplementary File 1), or unique sequence groups generated by Trinity. The assembled transcriptome has an average sequence length of $786 \mathrm{bp}$ and an N50 of $1173 \mathrm{bp}$. By 
Table 1 Sequencing Library and Mapping Information

\begin{tabular}{lllll}
\hline Library & Cell Type & Replicate & Number of read pairs & Mapping Rate \\
\hline MP53 & P & P1 & $38,227,788$ & $84.3(32231481)$ \\
MP54 & N & N1 & $21,682,428$ & $84.8(18380876)$ \\
MP56 & T & T1 & $32.6(28904539)$ \\
MP57 & T & T2 & $35,013,041$ & $82.0(30121670)$ \\
MP58 & Gm & G1 & $36,731,322$ & $80.5(29794591)$ \\
MP59 & Gm & G2 & $37,025,549$ & $81.0(22902730)$ \\
MP60 & G3 & $28,269,748$ & $78.0(25190050)$ \\
MP61 & N & N3 & $32,306,265$ & $86.3(29329162)$ \\
MP62 & T3 & $33,965,761$ & $84.7(23332299)$ \\
MP64 & T & R1 & $27,553,529$ & $93.6(32143423)$ \\
MP65 & Retzius & R2 & $34,354,179$ & $93.2(38190425)$ \\
MP67 & Retzius & P3 & $40,990,667$ & $93.8(39315980)$ \\
\hline
\end{tabular}

comparison, the average transcript length of the 24,432 predicted genes (gene models) in the draft genome assembled for the leech species Helobdella robusta is 1.2 $\mathrm{kb}$ and their N50 is $1763 \mathrm{bp}$. Thus, we attribute the discrepancy between the number of "genes" in the H. verbana transcriptome and the number of gene models in the Helobdella genome to a failure to assemble full Hirudo transcripts, so that two or more "genes" correspond to different parts of a single predicted Helobdella gene. This is supported by the fact that in a reduced dataset of only those transcripts that contain an open reading frame of 50 amino acids or more as measured by Transdecoder (https://github.com/TransDecoder/ TransDecoder/wiki) there are 35,590 Trinity "genes" and 89,363 "transcripts", suggesting that the remaining genes are either non-coding sequence (long non-coding RNAs or UTR) or misassembled transcripts (Supplementary File 2). As all of the transcripts had total read support of 1 TPM (Transcript per Million [31];) or greater, it is likely that they are short or 3 '-biased. It is also possible that different potential splice isoforms were separated into separate "genes" when in fact they arise from the same genomic locus. In any case, the sequencing depth achieved by pooling large numbers of phenotypically distinct cell types should prove an important resource for future profiling work at the level of individual neurons.

Our BLAST analysis of the transcriptome assembly revealed that 17,632 (34\%) of the "genes" had a significant (e-value $<0.05)$ BLAST hit in the $H$. robusta gene model database; consistent with the reasoning presented above, there were many cases in which two or more Hirudo "genes" mapped to a single Helobdella gene model. As two Hirudo medicinalis genomes were recently published [32,33], we also compared the transcriptome to the gene models of one [33] and showed that 28,021 (54\%) of the "genes" had a significant BLAST hit. A similar but slightly lower fraction of the Hirudo "genes"
15,646 (30\%) had a significant BLAST hit against the SwissProt non-redundant database [34]; we speculate that many of the Hirudo "genes" that failed to map to either the Helobdella or Hirudo genomes or the SwissProt database represent the more rapidly diverging untranslated regions (UTRs) of the transcripts. In the reduced ORF-filtered transcriptome the BLAST rates were 17 , 632 (50\%) for Helobdella proteins, 28,020 (79\%) for $H$. medicinalis proteins, and 15,646 (44\%) for the SWISSProt database. Finally, when we mapped the original sequence libraries back to the transcriptome we found that all libraries mapped within a range of 78 to $93.6 \%$, suggesting that the transcriptome is representative of the input sequences.

To test the prediction that different cell types have distinct transcriptional profiles, we performed a MultiDimensional Scaling (MDS) analysis of the twelve libraries on genes that had a TPM $>2$. As expected, the twelve samples segregated into groups roughly corresponding to cell type. The highest degree of internal consistency was for the three $\mathrm{T}$ cell transcriptomes and for the three $\mathrm{Gm}$ transcriptomes. The Rz cells exhibited the most divergent transcriptional profiles from the other sample types, consistent with their neurosecretory function (Fig. 1b). The $\mathrm{N}$ and $\mathrm{P}$ cells showed the highest similarity to each other, which correlates with their electrophysiological similarities.

\section{Comparisons among cell types reveal clusters of differentially expressed genes}

To determine the functional implications of the differences in transcriptional profiles, we performed all ten possible pairwise comparisons of the five different transcriptomes. These comparisons yielded a set of 3565 differentially expressed genes (Table 2; see Materials and Methods for details; Supplementary File 3). The total number of genes found in all of the pairwise 
Table 2 Numbers of Differentially Enriched Genes in Pairwise Transcriptome Comparisons

\begin{tabular}{llllll}
\hline & $\mathbf{G m}$ & $\mathbf{N}$ & $\mathbf{P}$ & $\mathbf{R}$ & $\mathbf{T}$ \\
\hline $\mathbf{G m}$ & 0 & 780 & 1203 & 1521 & 251 \\
$\mathbf{N}$ & & 0 & 166 & 297 & 328 \\
$\mathbf{P}$ & & & 0 & 227 & 952 \\
$\mathbf{R}$ & & & & 0 & 1504 \\
$\mathbf{T}$ & & & & & 0 \\
\hline
\end{tabular}

comparisons summarized in Table 2 was 7229, reflecting the fact that many of the 3565 differentially expressed genes occurred in more than one of the pairwise comparisons.

The similarities and differences in overall transcriptional profiles among the samples, and in the expression of individual genes across samples, were explored using a hierarchical clustering analysis on the biological replicates and on the individual expression profiles of the differentially expressed genes described above (Fig. 2a). Individual samples grouped primarily by cell type (Fig. 1b).

Naively, one might have expected to obtain five clearly separated clusters of similar gene expression profiles, corresponding to the five sample types. But this was not the case--there was no discrimination height on the gene clustering tree that delineated five clusters correlating with the five sample types (Fig. 2b). At least in retrospect, this initial expectation seems unlikely, given the fact that multiple genes showed up in more than one pairwise comparison (Table 2), and also given the heterogeneity of cell types within the Gm samples. Instead, once the genes were clustered by similarities in expression, we chose a discrimination height on the tree (dotted line in Fig. 2b) that highlighted at least one distinct cluster for each cell type, giving nine clusters of similarly expressed genes for further analysis (Fig. 2b and S2).

The mean expression patterns of the clusters (Fig. 2c and $\mathrm{S} 2$ ) reveal that most of them contain genes that are enriched in particular sample types: genes in Clusters 2

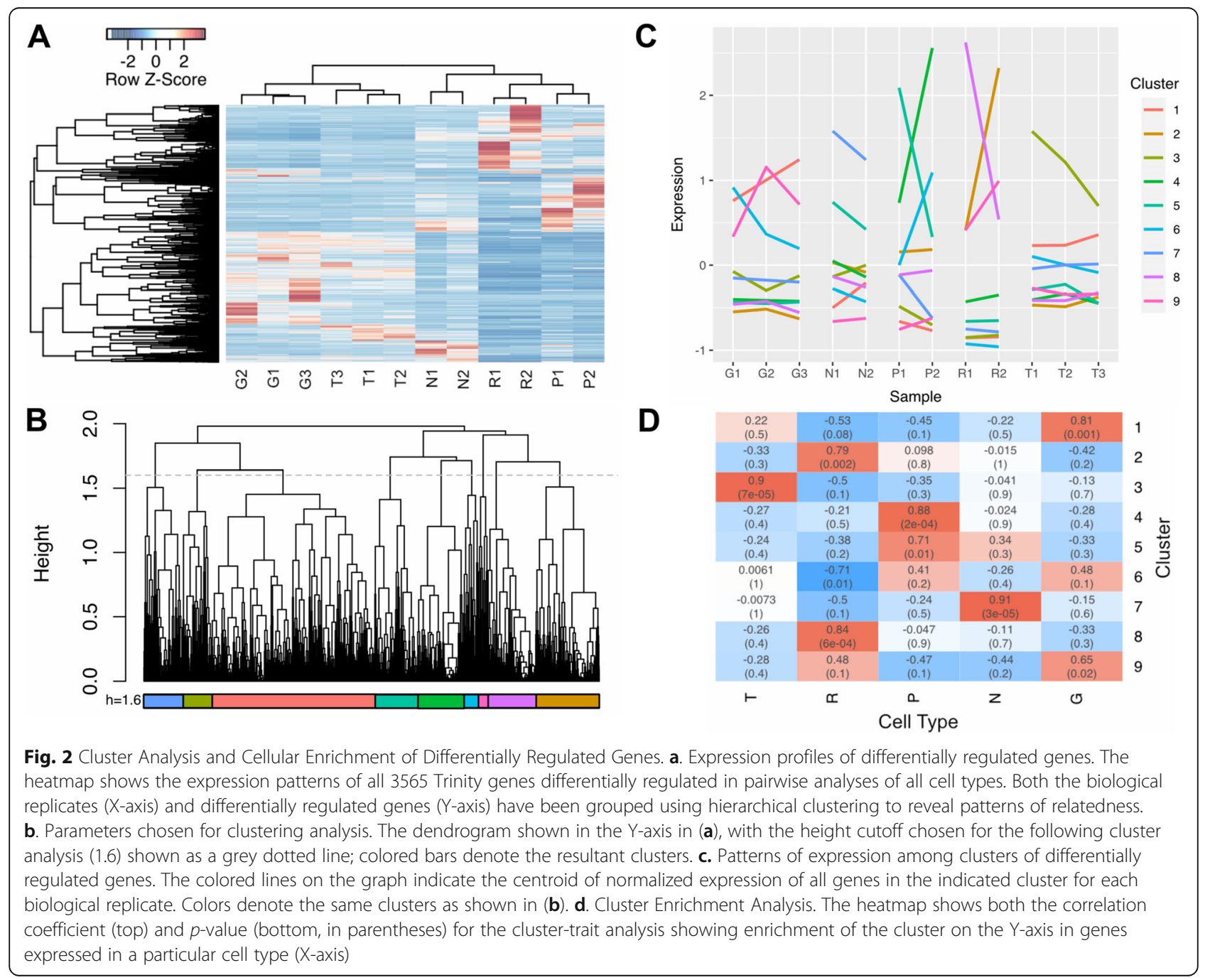


and 8 tended to be enriched in Retzius cells; genes in Clusters 4 and 5 tended to be enriched in P cells; genes in Cluster 3 tended to be enriched in T cells; genes in Cluster 7 tended to be enriched in N cells; genes in Clusters 1 and 9 tended to be enriched in Gm samples; and those in Cluster 6 were only statistically associated with downregulation in Retzius cells.

To assess the statistical significance of the correlations between expression of the genes in each cluster with the enrichment in a particular cell type, we performed a cluster-trait analysis on the gene expression clusters (Fig. 2d, see Methods). GO Term enrichment analysis revealed that only 3 clusters $[1,2,8]$ had significantly enriched GO Terms (Supplementary File 5).

In situ hybridization reveals gene expression predicted by transcriptional profiling

To test the validity of the gene expression profiles emerging from the RNASeq analyses, we performed ISH on isolated Hirudo ganglia, using probes for genes selected from various clusters (Table 3). This validation was of particular importance because of the possibility for errors in generating the pools of cells used for transcriptional profiling. For example, while the crosscontamination rate for the Rz samples should be near zero, because these cells are unmistakable due to their uniquely large size and position in the ganglion, $\mathrm{P}$ cell samples might be contaminated with occasional Leydig cells [35], which are similar in size and position to lateral $\mathrm{P}$ cells, notwithstanding differences in pigmentation. Similarly, rare cross-contamination of $\mathrm{T}$ and $\mathrm{N}$ neuron samples may occur because these two cell types, while differing in size, occupy adjacent and variable locations in the anterior portion of the ganglion.

For our ISH analysis, we sought to focus on genes with relatively abundant transcripts and relatively selective expression in one of the four cell types under investigation. For this purpose, we first re-examined the set of 3565 differentially expressed genes to identify those with: 1) BLAST e-values below 0.05 to both the SwissProt and Helobdella protein databases; 2) TPM counts above 20 in at least 2 biological replicates, and; 3) a standard error of the mean TPM count not exceeding $40 \%$ of the mean of the cell type with the highest expression level. Finally, we excluded genes from Cluster 6, which was not significantly associated with any of the four neuronal subtypes of interest, and Clusters 1 and 9, because they represents genes that were not expected to be enriched in the neuronal phenotypes of interest, because they are associated primarily with the $\mathrm{Gm}$ samples. From the resulting list we also excluded those with GO Terms indicating mitochondrial or ribosomal functions, leaving a list of 415 candidates (Supplementary File 4) from which we chose genes of interest as described below for ISH analysis (Table 3).

Current ISH protocols for adult Hirudo ganglia require the microsurgical removal, prior to fixation, of a protective sheath that encapsulates the ganglion [36-38]. Unfortunately, this results in the occasional loss or displacement of cell bodies, especially near the lateral edges of the ganglion where the cuts are made. Thus, the counts and spatial distribution of neuronal cell bodies observed in ISH experiments are more variable than in intact ganglia. Nonetheless, as described below, all of the genes tested exhibited characteristic patterns of

Table 3 Genes Used for in situ Hybridization Verification of RNASeq Libraries

\begin{tabular}{|c|c|c|c|c|c|c|c|c|c|}
\hline \multirow[t]{2}{*}{ Common Name } & \multirow[t]{2}{*}{ Cluster } & \multirow[t]{2}{*}{ Trinity Gene ID } & \multirow[t]{2}{*}{$\begin{array}{l}\text { Helro BLAST } \\
\text { (evalue) }\end{array}$} & \multirow{2}{*}{$\begin{array}{l}\text { SWISS Prot } \\
\text { BLAST } \\
\text { (evalue) }\end{array}$} & \multicolumn{5}{|c|}{$\begin{array}{l}\text { Average Expression in Each Cell Type in TPM } \\
\text { (Transcripts per Kilobase Million) +/- SEM }\end{array}$} \\
\hline & & & & & $\mathbf{T}$ & $\mathbf{P}$ & $\mathrm{N}$ & $\mathrm{Gm}$ & $\mathbf{R}$ \\
\hline $\begin{array}{l}\text { Aromatic Amino Acid } \\
\text { Decarboxylase }\end{array}$ & 2 & comp24417_c0 & $\begin{array}{l}\text { jgi|Helro1||186120 } \\
(6.91 \mathrm{E}-70)\end{array}$ & $\begin{array}{l}\text { P14173.1 } \\
(3.12 \mathrm{E}-6)\end{array}$ & $\begin{array}{l}13.7+/- \\
2.7\end{array}$ & $\begin{array}{l}8.2+1- \\
2.3\end{array}$ & $\begin{array}{l}17.7+/- \\
3.1\end{array}$ & $\begin{array}{l}12.5 \\
+/-2.4\end{array}$ & $\begin{array}{l}2432.5 \\
+/-465.0\end{array}$ \\
\hline $\begin{array}{l}\text { Tryptophan } \\
\text { Hydroxylase }\end{array}$ & 2 & comp20323_c0 & jgi|Helro1|79745 (0) & $\begin{array}{l}\text { P70080.1 } \\
(1.13 E-15)\end{array}$ & $\begin{array}{l}5.7+/- \\
1.0\end{array}$ & $\begin{array}{l}5.5+/- \\
1.0\end{array}$ & $\begin{array}{l}5.2+/- \\
2.2\end{array}$ & $\begin{array}{l}32.5 \\
+/-3.1\end{array}$ & $\begin{array}{l}929.0+/- \\
28.0\end{array}$ \\
\hline HCN Channel & 4 & comp20462_c0 & $\begin{array}{l}\text { jgi|Helro1 } \mid 98055 \\
(8.90 \mathrm{E}-126)\end{array}$ & $\begin{array}{l}\text { O88703.1 } \\
(10 E-101)\end{array}$ & $\begin{array}{l}2.8+/- \\
1.0\end{array}$ & $\begin{array}{l}31.6+/- \\
12.9\end{array}$ & $\begin{array}{l}7.4+/- \\
2.0\end{array}$ & $\begin{array}{l}1.3+/- \\
0.3\end{array}$ & $\begin{array}{l}0.5+/- \\
0.2\end{array}$ \\
\hline $\begin{array}{l}\text { Voltage-Gated } \\
\text { Potassium Channel }\end{array}$ & 4 & comp25036_c1 & $\begin{array}{l}\text { jgi|Helro1|64112 } \\
\text { (4.92E-83) }\end{array}$ & $\begin{array}{l}\text { Q9H252 } \\
(3.26 \mathrm{E}-52)\end{array}$ & $\begin{array}{l}6.9+1- \\
2.0\end{array}$ & $\begin{array}{l}26.1+/- \\
11.0\end{array}$ & $\begin{array}{l}5.3+/- \\
3.8\end{array}$ & $\begin{array}{l}1.22 \\
+/-0.3\end{array}$ & $\begin{array}{l}0.0+1- \\
0.0\end{array}$ \\
\hline Protocadherin & 4 & comp15454_c0 & $\begin{array}{l}\text { jgi|Helro1|69346 } \\
\text { (1.50E-77) }\end{array}$ & $\begin{array}{l}\text { Q9BZA7.1 } \\
(2.58 E-48)\end{array}$ & $\begin{array}{l}32.6+/- \\
13.8\end{array}$ & $\begin{array}{l}511.8 \\
+/-68.4\end{array}$ & $\begin{array}{l}235.6 \\
+/-92.2\end{array}$ & $\begin{array}{l}14.3 \\
+/-1.8\end{array}$ & $\begin{array}{l}7.8+/- \\
5.6\end{array}$ \\
\hline Collagen-alpha & 3 & comp13598_c0 & $\begin{array}{l}\text { jgi|Helro1|110155 } \\
(2.52 \mathrm{E}-17)\end{array}$ & $\begin{array}{l}\text { Q17RW2.2 } \\
(3.39 \mathrm{E}-11)\end{array}$ & $\begin{array}{l}23.5+/- \\
5.7\end{array}$ & $\begin{array}{l}0.2+/ \\
0.1\end{array}$ & $\begin{array}{l}5.2+/- \\
1.0\end{array}$ & $\begin{array}{l}0.6+/ \\
0.3\end{array}$ & $\begin{array}{l}0.04+/- \\
0.04\end{array}$ \\
\hline $\begin{array}{l}\text { Inositol Triphosphate } \\
\text { Receptor }\end{array}$ & 3 & comp24045_c0 & $\begin{array}{l}\text { jgi|Helro1|162846 } \\
(1.84 \mathrm{E}-69)\end{array}$ & $\begin{array}{l}\text { P70227.3. } \\
(1.44 \mathrm{E}-06)\end{array}$ & $\begin{array}{l}521.5+/- \\
186.7\end{array}$ & $\begin{array}{l}22.9+/- \\
5.6\end{array}$ & $\begin{array}{l}105.8 \\
+/-17.4\end{array}$ & $\begin{array}{l}6.9+/- \\
1.3\end{array}$ & $3.0+/ 2.7$ \\
\hline Annelid Hypothetical & 5 & comp21991_c0 & $\begin{array}{l}\text { jgi|Helro1|169916 } \\
(6.50 \mathrm{E}-29)\end{array}$ & None & $\begin{array}{l}42.1+/- \\
14.8\end{array}$ & $\begin{array}{l}179.6 \\
+/-80.7\end{array}$ & $\begin{array}{l}103.5 \\
+/-10.0\end{array}$ & $\begin{array}{l}7.3+/- \\
0.7\end{array}$ & $\begin{array}{l}1.0+/- \\
0.4\end{array}$ \\
\hline
\end{tabular}


expression in the ganglion that closely matched the predicted expression from the RNASeq data. In what follows, the gene names used result from molecular phylogenetic and BLAST analyses, as will be explained later in this paper.

Consistent with the serotonergic character of the $\mathrm{Rz}$ neurons (e.g., [24, 39]), genes encoding proteins involved in biosynthesis and transport of serotonin were prominent components of their transcriptional profile. In particular, Cluster 2 was enriched for transcripts encoding tryptophan hydroxylase (hve-tph, Trinity Gene ID comp20323_c0) and dopa decarboxylase (hve-ddc, comp24417_c0), two enzymes required for serotonin biosynthesis.

Hve-tph transcripts were readily detected by ISH in the giant Rz neurons, which occupy a prominent anteromedial location on the ventral surface of the ganglion. A strong ISH signal for hve-tph was also observed in two other pairs of smaller serotonergic neurons (cell pairs 21 and 61 [40];; Fig. 3a). Surprisingly, however, while hve$d d c$ was also readily detected in Rz neurons, we failed to detect an ISH signal for this transcript in cells 21 or 61 (Fig. 3b). The contrast between the ISH results for hvetph and $h v e-d d c$ was consistent with the differences in the transcript levels obtained from the Gm samples-those samples showed significantly higher counts for hve-tph transcripts than did the $\mathrm{T}, \mathrm{P}$, or $\mathrm{N}$ samples (Fig. $3 \mathrm{a})$, whereas the counts for $h v e-d d c$ were uniformly low in all but the Rz samples (Fig. 3b).

ISH for three genes whose transcripts were relatively abundant and enriched in the $\mathrm{P}$ transcriptomes showed expression in both the $\mathrm{P}$ and $\mathrm{N}$ neurons (Fig. 3c-e). These genes, all associated with Cluster 4, encode a protocadherin homolog (hve-pcad1, comp15454_c0); a hyperpolarization-activated, cyclic nucleotide-gated cation channel (hve-hcn4, comp20462 $\mathrm{c} 0$ ); and a voltage-gated potassium channel (hve-vgkc1, comp25036_c1). Probes for these three genes labeled combinations of $\mathrm{N}$ and $\mathrm{P}$ cells that varied somewhat from ganglion to ganglion and even across the midline of individual ganglia (Fig. 3c-e). We attribute this variability, at least in part, to loss or displacement of cells caused by desheathing the ganglia, but an alternative and interesting possibility is that gene expression differs between the medial and lateral members of the $\mathrm{N}$ and $\mathrm{P}$ cell pairs. Pharmacological and anatomical studies have revealed differences in innervation and sensory coding by the medial and lateral $\mathrm{N}$

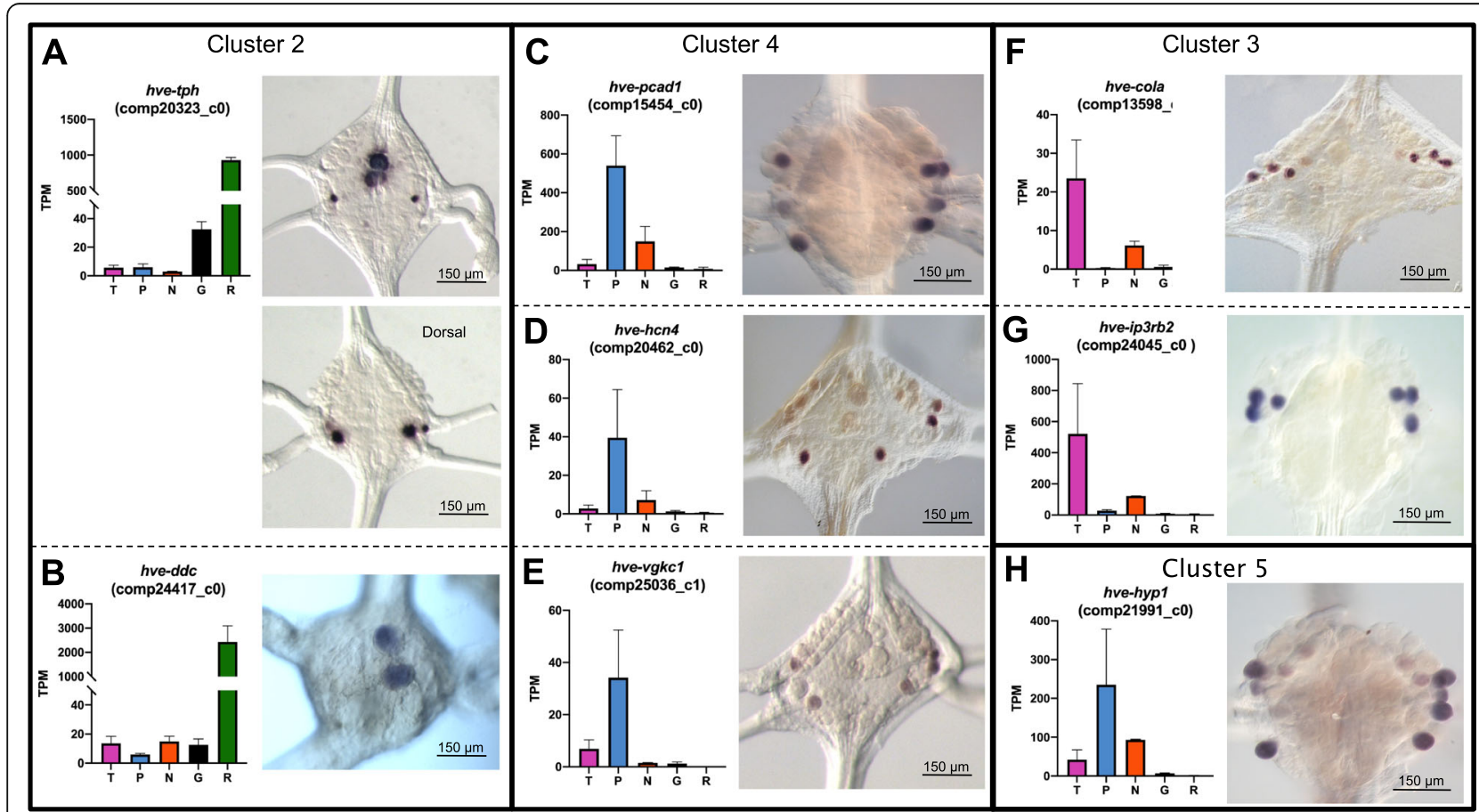

Fig. 3 In situ hybridization (ISH) verification of expression patterns found by RNASeq. Eight Trinity genes from four clusters were chosen to represent the widest variety of potential staining patterns. $\mathbf{a}-\mathbf{h}$. In each panel: the graph at left denotes the expression levels of a Trinity gene in the RNASeq analysis, with the cell type on the X-axis and the average normalized read count of the transcript in transcripts per kilobase million (TPM) on the Y-axis; error bars denote the standard error of the mean; the micrograph at right shows a typical ISH staining pattern for the Trinity gene in an adult $H$. verbana (Hve) ganglion. All ganglia are oriented ventral-side up unless otherwise indicated. Tph= tryptophan hydroxylase, $d d c=$ dopa decarboxylase, $p c a d 1=$ protocadherin 1, hcn $4=$ hyperpolarization-activated cyclic nucleotide-gated channel 4, vgkcl=voltage-gated potassium channel 1, cola = collagen-alpha, ip3rb2 = inositol triphosphate receptor b2, hyp $1=$ hypothetical 1 
cells [22], which we expect to reflect differences in their gene expression patterns.

In the transcriptional profiles of $\mathrm{T}$ neurons, two genes in Cluster 3 stood out rather unexpectedly, because their biochemical functions seem to correspond to ubiquitously expressed "housekeeping" genes. One encodes a putative collagen-alpha (hve-cola, comp13598_c0) and the other encodes a putative receptor for inositol triphosphate (hve-ip3rb2, comp24045_c0). For both these genes, the ISH pattern was exceptionally clear, showing three bilateral pairs of labeled neurons in the anterolateral portions of the ganglia correlating with the known positions of the $\mathrm{T}$ neuron cell bodies (Fig. $3 \mathrm{f}$ and g). In light of these results, we speculate that the seemingly increased transcript counts for these genes in the $\mathrm{N}$ cell transcriptomes (Fig. 3f and g) may represent errors in cell identification during sample preparation.

As a further test for the inferred identity of the neurons expressing hve-ip3rb2, and to illustrate the potential for combining molecular and physiological approaches in Hirudo ganglia, we used standard techniques to identify $\mathrm{T}$ cells by intracellular electrical recordings, and then labeled the identified $\mathrm{T}$ neurons by iontophoretic injection of a charged, fixable fluorescent dextran (see Materials and Methods for details). When such preparations were fixed and processed for hveip3rb2 ISH, the ISH product co-localized with the fluorescently labeled neurons, as expected (Fig. 4).

In addition to the genes discussed above, we also carried out ISH for a transcript representing a gene for which orthologs are known only from other annelid species. Such genes are candidates for evolutionary novelties, representing hypothetical (hyp) proteins. We chose one such candidate (comp21991_c0, hve-hyp1) from Cluster 5. While hve-hyp1 did not satisfy the criteria for selection above due to a lack of similarity to any proteins in the SWISS-Prot database, we chose it for further analysis to begin to probe how lineage-specific genes may be involved in neuronal specification and function.
Consistent with the read counts (Fig. 3h), hve-hyp1 was expressed primarily in $\mathrm{N}$ and $\mathrm{P}$ neurons (Fig. $3 \mathrm{~h}$ ).

To explore the extent to which the neuronal markers identified in Hirudo may be applicable to other leech species, we identified Helobdella orthologs for several of the differentially expressed Hirudo genes described above, and then performed ISH for their transcripts on Helobdella embryos at stage 10-11 of development, by which time the nervous system is fairly well differentiated and yet ISH can be carried out on intact embryos without dissection (Fig. S2).

As expected, two Rz markers (hau-tph and hau-ddc) were expressed in the highly conserved serotonergic $\mathrm{Rz}$ neurons [41]. Intriguingly, hau-tph was expressed also in the location of previously described ventrolateral, dorsolateral, and posteromedial serotonergic neurons (Fig. S2 [41];), but as we had observed for Hirudo (Fig. 3), hau$d d c$ was not expressed in these cells.

The expression patterns observed for the Helobdella genes hau-pcad1 and hau-hcn4 were also similar to those of their Hirudo orthologs. Because ISH on Helobdella was performed without dissecting the sheath surrounding the ganglion, the expression patterns for these genes were not disrupted by loss or displacement of cells during processing, and clearly repeating patterns were observed. For hau-pcad1, four pairs of cells were observed in most ganglia, in positions expected for the bilateral pairs of medial and lateral $\mathrm{N}$ and $\mathrm{P}$ neurons, but the expression levels were lower in the putative medial $\mathrm{N}$ cell than in the other three cells. For hau-hcn4 three pairs of cells were observed in most ganglia, corresponding to both of the putative $\mathrm{P}$ neurons and the lateral but not the medial $\mathrm{N}$ neuron.

In contrast to the results for putative $\mathrm{Rz}, \mathrm{N}$ and $\mathrm{P}$ neuron markers, neither of the $\mathrm{T}$ cell markers surveyed (hau-ip3rb2 and hau-cola) showed noticeably stronger expression in any particular set of ganglionic neurons (Fig. S2). This result suggests that either the $\mathrm{T}$ cells in Helobdella use different genes for their specification or

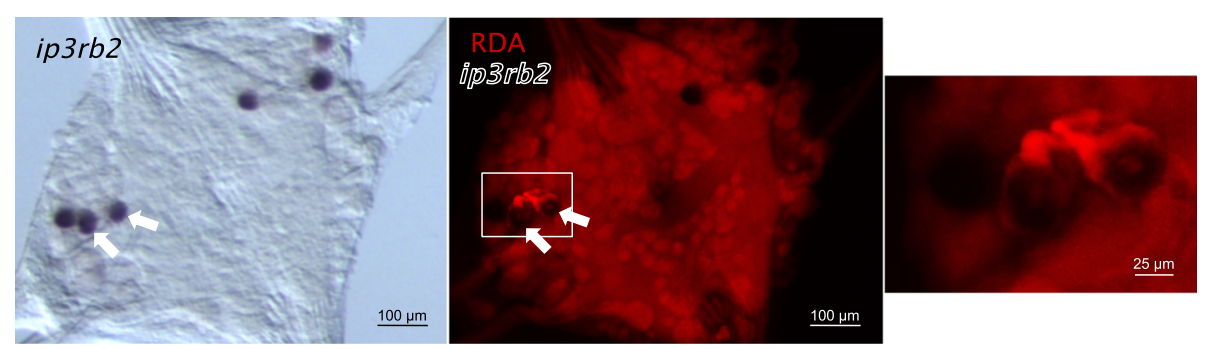

Fig. 4 The ip3rb2 transcript localizes to T neurons. Left panel, brightfield micrograph: ISH for ip3rb2 shows three bilateral pairs of neurons as expected for the T cells. Center panel, fluorescence micrograph: prior to the in situ staining, two of the three T neurons on the left hand side (white arrowheads) had been injected with RDA (red). Right panel, fluorescence micrograph: magnified view of the boxed region in center panel shows that RDA signal in neuronal somata is masked by ISH product. Background signal is due to autofluorescence arising during ISH processing 
function, or that the $\mathrm{T}$ cells lag behind other neurons in their development and were not yet expressing these genes at stage 11 .

\section{Molecular phylogeny of amino acid decarboxylases (AADs)}

It is paradoxical that the aromatic amino acid decarboxylase gene enriched in $\mathrm{Rz}$ neurons was not detected in other known serotonergic neurons in either Hirudo or Helobdella. One explanation for this observation is that the other neurons are recycling serotonin, taking up serotonin released by the neuromodulatory Rz neurons and then releasing it from their own synapses. This seems unparsimonious, however, given that the non- $\mathrm{Rz}$ serotonergic neurons do express tryptophan hydroxylase in both species.

Alternatively, these neurons may use a different aromatic AAD to synthesize serotonin. The Helobdella genome encodes four genes annotated as aromatic AADs (AAADs). Three of these genes (JGI gene models 84403, 84539 and 101612) represent comparatively recent duplication events--they are adjacent to one another on genome scaffold 40 and exhibit $57-68 \%$ amino acid sequence identity. The fourth gene (JGI gene model 186120), which lies on a separate scaffold and shows only $41-52 \%$ sequence identity to the other three, is the ortholog of $h v e-d d c$, the gene expressed in Rz neurons.

To explore this issue further, we constructed a molecular phylogeny for the set of AAD sequences obtained by BLASTing a database of non-redundant protein sequences from two model organisms (mouse Mus musculus and fruit fly Drosophila melanogaster), and five sequenced lophotrochozoan species (Helobdella robusta, polychaete annelid Capitella teleta, bivalve Crassostrea gigas, cephalopod Octopus bimaculoides, and gastropod Lottia gigantea). Mus and Drosophila were chosen to represent the deuterostomes and ecdysozoans, respectively, because the AAADs used for serotonin biosynthesis in these species are known [42, 43].

The genes recovered form two main clades (Fig. 5). One clade comprises acidic amino acid decarboxylases, including a paraphyletic group of glutamic acid decarboxylases (GADs) used to synthesize the neurotransmitter GABA. This GAD subclade included sequences from five of the species. The other clade comprises the AAADs. The AAAD clade contains three subclades with broad phylogenetic representation--histidine decarboxylases (HDs, used in histamine biosynthesis, apparently missing in leeches), tyrosine decarboxylases (TDs, used in tyramine and octopamine biosynthesis) and DOPA decarboxylases (DDCs, used in dopamine and serotonin biosynthesis). The gene expressed in leech $\mathrm{Rz}$ neurons belongs to the DDC clade, as do the mouse and fly genes used in serotonin biosynthesis. The other three leech
AAADs group within the TD subclade. We speculate that one or more of these genes has been co-opted for serotonin biosynthesis in the non-Rz serotonergic neurons but the question remains open. Firstly, the Hirudo transcriptome generated here did not contain identifiable orthologs for all three of the Helobdella TD genes. Moreover, for the one Hirudo transcript (comp21658_ c0) that did show sequence similarity to one of the Helobdella gene models (101612), the normalized read counts were very low (less than 4 in all samples) in all $\mathrm{Gm}$ samples, compared with normalized hve-tph read counts of more than 30 .

\section{Expansion of the hen gene family in leech}

One of the prominently upregulated genes in the P and, to a lesser extent, the $\mathrm{N}$ cells was a hyperpolarizationactivated cyclic nucleotide-gated ( $\mathrm{HCN})$ channel (Figs. 3 and S2). This channel is a candidate for mediating a prominent, hyperpolarization activated "sag" current that is characteristic of leech P neurons [44] and heart interneurons [45]. However, evidence of a hyperpolarizationactivated current has also been found in the T, P, N, and Rz neurons $[18,46]$.

In our transcriptome, we found four distinct additional $h c n$ "genes", and examination of another transcriptome [47] yielded two more, suggesting that Hirudo contains at least seven $\mathrm{HCN}$ genes. Comparison of these transcripts to the Helobdella genome revealed the presence of seven orthologous, genomically distinct, $\mathrm{HCN}$ channel genes and one additional gene as yet found only in Helobdella. While this is not a large gene family in absolute terms, it still represents a significant expansion, given that the largest number found in an animal genome to date is four (for mammals; Fig. 6, expanded tree in Fig. S4). Our phylogenetic analysis revealed that the $\mathrm{HCN}$ gene family has expanded independently in the annelid and vertebrate lineages. Moreover, the expansion of the $\mathrm{HCN}$ gene family in annelids appears to be quite recent, as the genome of another annelid (Capitella teleta) only encodes one HCN gene, and other lophotrochozoans have at most two (data not shown). Despite their relatively recent emergence, the seven $\mathrm{HCN}$ genes in leech appear to have divergent patterns of expression (Fig. 6a). Thus, these results exemplify how gene family diversification may contribute to cell phenotype diversification.

\section{A phylogenetically distinct IP3 receptor (IP3R) sub-type is preferentially expressed in touch sensitive neurons}

Finding an IP3R-encoding transcript among the most prominent elements of the $\mathrm{T}$ neuron transcriptional profile, as judged by both relative enrichment and transcript abundance, was unexpected, because we usually think of the IP3Rs as ubiquitously expressed regulators of 


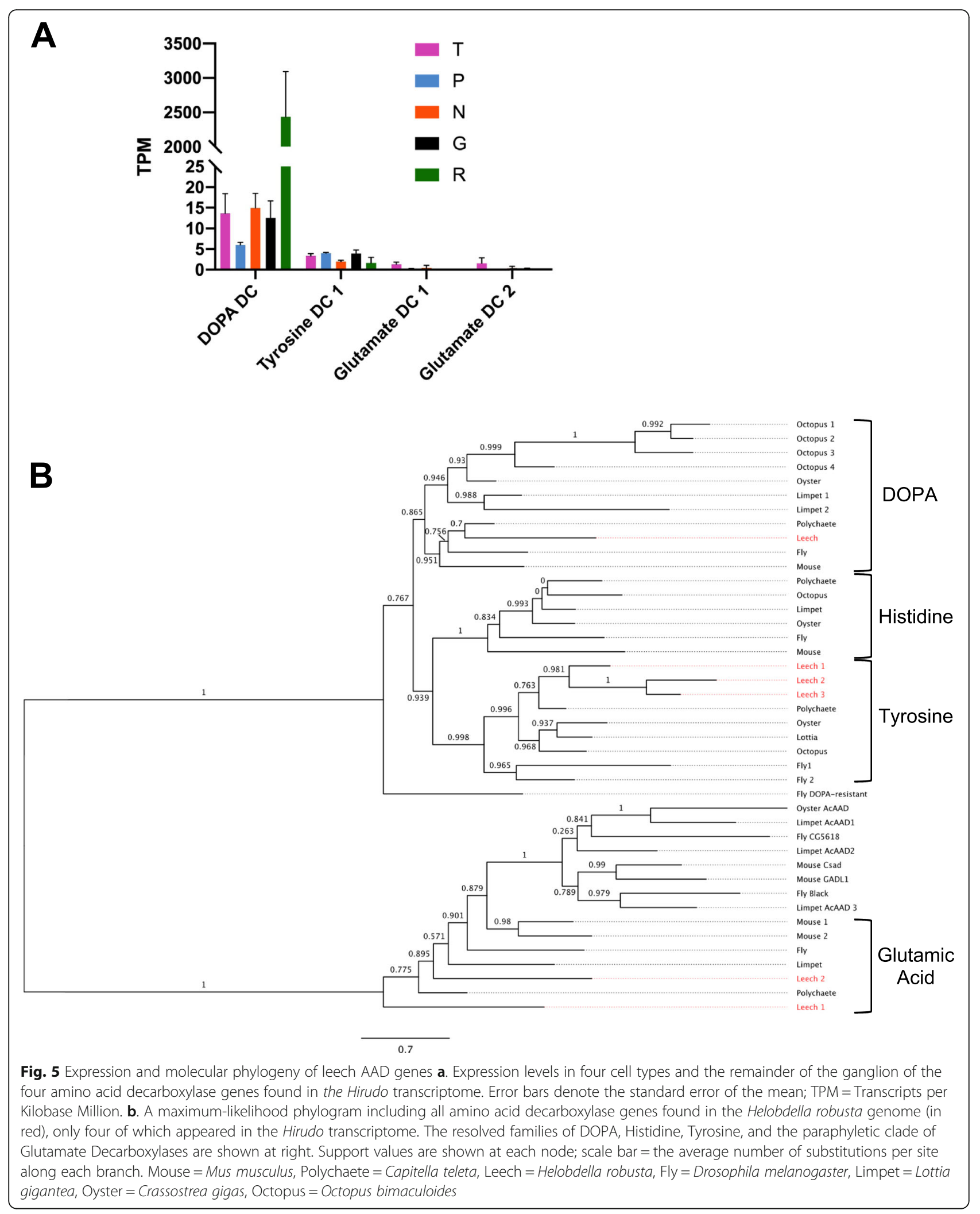




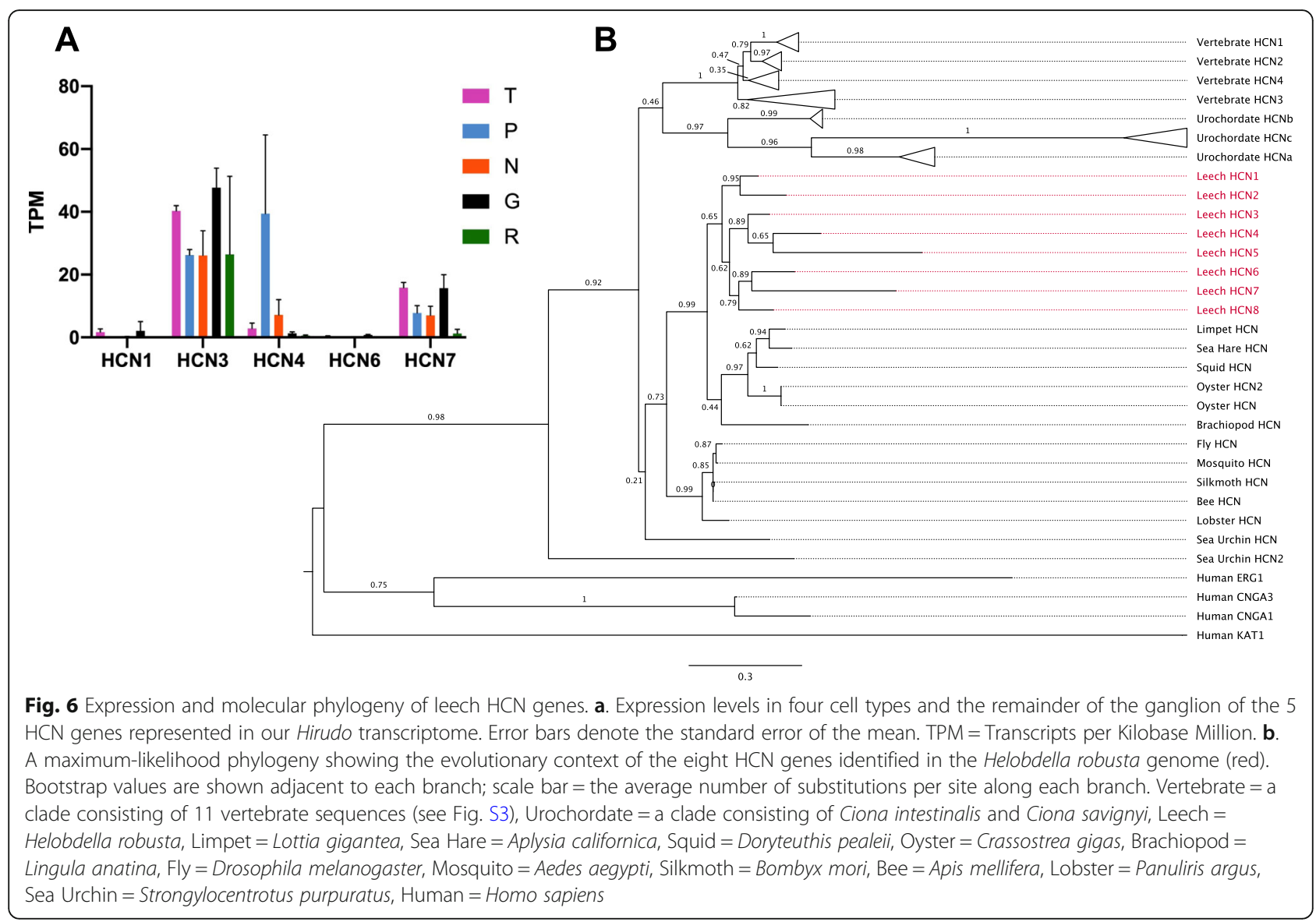

calcium release from endoplasmic reticulum [48]. Therefore, having validated this result by ISH (Figs. 3 and 4), we explored the diversity of this gene family in the Hirudo transcriptome and the Helobdella genome.

Previous work suggests that the bilaterian ancestor had three types of IP3 receptors: IP3RA, IP3RB, which has been lost in the vertebrates, and ryanodine receptors (RyaR; Fig. 7 [49];). Our initial BLAST analyses revealed 20 transcripts in the Hirudo transcriptome that BLAST to the IP3R family, compared with five gene loci in the Helobdella genome. As IP3Rs are typically large proteins, these five genes were often spread out over two or more (machine annotated) gene models in the Helobdella genome. Accordingly, the conceptually translated polypeptides of the 20 Hirudo ip $3 r$ transcripts map to different regions of four of the five IP3Rs inferred from the Helobdella genome, so our data are consistent with a set of at least four mutually orthologous IP3Rs in the two leech species.

The five Helobdella IP3Rs include two IP3RA genes, two IP3RB genes, and one RyaR (Fig. 7). Our phylogenetic analysis indicates that the T-enriched IP3R is ip3rb2. The IP3RB family of IP3Rs is understudied because it has not been reported in the vertebrates and is also absent in D. melanogaster and C. elegans. Given the absence of an ISH signal for ip3rb2 in $\mathrm{N}$ neurons, we suspect that the apparently significant levels of $i p 3 r b 2$ in the $\mathrm{N}$ cell transcriptome may represent contamination of the $\mathrm{N}$ cell pools by mis-identified $\mathrm{T}$ neurons. In addition to ip3rb2, the $\mathrm{T}$ cells express ip3ra1 and ip3ra2 at levels comparable to the other profiled neurons and the ganglion as a whole.

\section{Canonical mechanoreceptor candidate genes in the transcriptional profiles of the leech nervous system}

The $\mathrm{T}, \mathrm{P}$ and $\mathrm{N}$ neurons in the leech nervous system provide a cellularly well-defined and accessible system in which to study the mechanisms of mechanotransduction in three discrete classes of sensory neurons. As a start toward this goal, we examined the transcriptional profiles for genes related to those that have been implicated in mechanotransduction in other systems, including members of the piezo, trp and deg/enac gene families. This approach is particularly relevant for the trp and enac gene families, where the large numbers of paralogs would otherwise complicate systematic analysis.

The piezos are an ancient gene family with homologs in protozoa, plants and animals [50]. The piezos encode multipass transmembrane proteins that are required for touch sensitivity in mammalian Merkel cells [51] and 


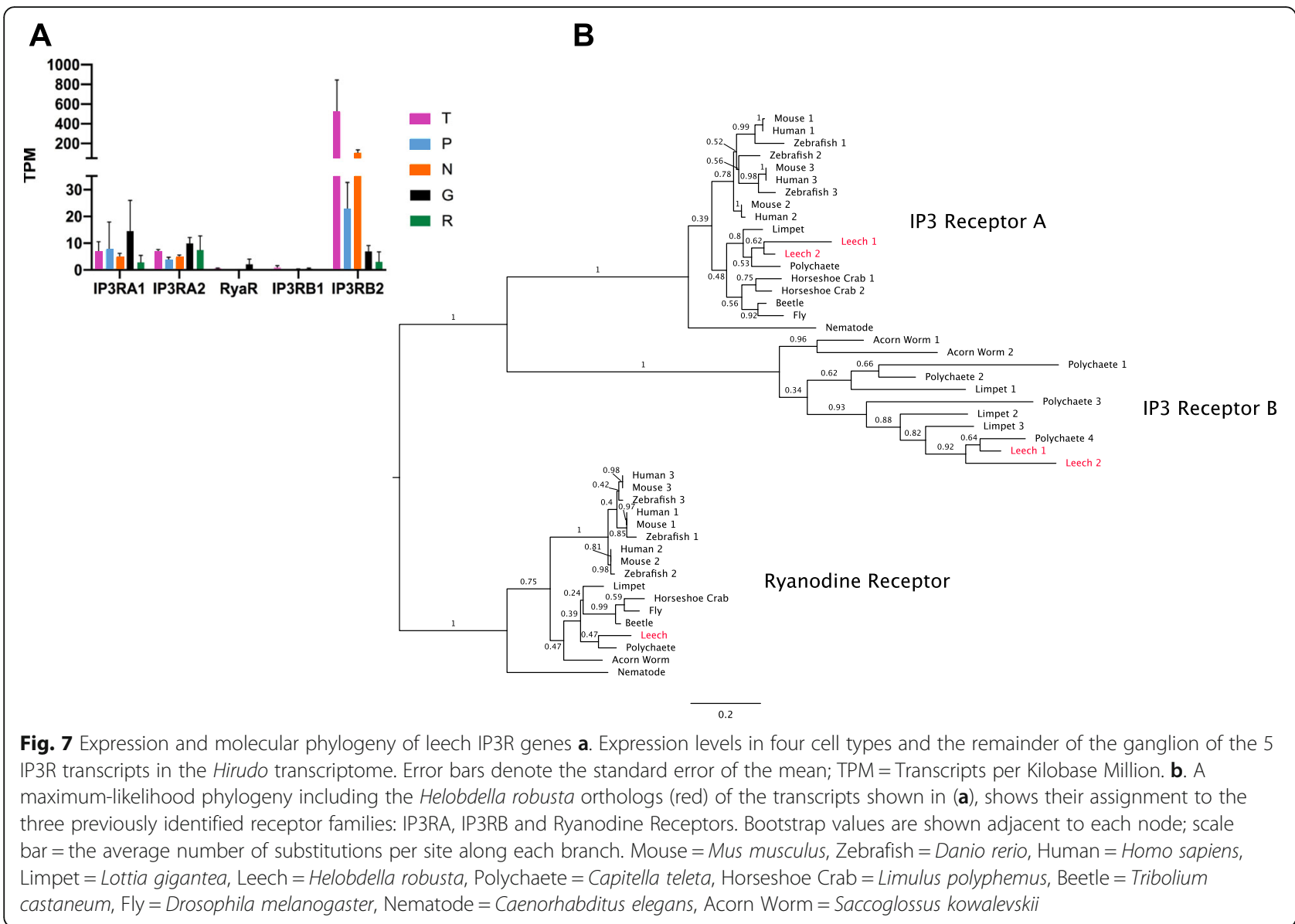

Drosophila nociceptors [52]. In contrast to the Trp and $\mathrm{Deg} / \mathrm{ENaC}$ channels discussed below, the diverse known physiological roles of Piezos all arise from mechanotransducer functions [53]. The Helobdella genome encodes two piezo genes, but a molecular phylogeny indicates that these are paralogs rather than orthologs of the two mammalian piezos (Fig. 8). The Hirudo ortholog of Helobdella piezo1, comp25540_c0, was among the list of differentially regulated genes and was grouped into cluster 1, as it is enriched in the Gm samples and T cells (Supplementary File 3). Normalized read counts for Hvepiezo1 are elevated 3-fold in T cells relative to the other neuronal phenotypes. Manual inspection of the Hirudo transcriptome revealed an ortholog of Helobdella piezo2 as well, but this gene was not differentially regulated in our analysis (Fig. 8). Thus, leech piezo1 in particular is a candidate for investigation as a mechanotransducer for touch in leech.

The transient receptor potential (trp) genes encode a diverse family of channel proteins, various members of which are implicated in transducing thermal, chemical and mechanical stimuli [54-57]. Seven subfamilies of Trp channels were present in the bilaterian ancestor (Trps A, C, M, ML, P, N, and V) [58, 59].
Many independent trp gene duplications have occurred as well. Thus, we find 16 trp sequences in the Hirudo nervous system transcriptome, each of which has an ortholog in the Helobdella genome; these 16 genes include representatives of all sub-families except $\operatorname{TrpN}$ and $\operatorname{TrpP}$ (Fig. 9). Duplicate genes are present within the $\operatorname{TrpC}, M$ and $V$ sub-families; for the $\mathrm{M}$ and $\mathrm{V}$ sub-families, these appear to represent duplications that had occurred in the bilaterian (M) and protostome (V) ancestors [58]. Eight genes in the Hirudo neuronal transcriptome lie within the $\operatorname{trp} A, V$, and $M$ families, which contain putative sensory genes in other organisms. Among these eight genes, only one, the Hirudo $\operatorname{trp} A 1$ transcript, was enriched in the $\mathrm{P}$ cell transcriptome to a statistically significant extent. Thus, this gene is another promising candidate for encoding a sensory transducer in leech.

Two Deg/ENaC channels, encoded by the mec4 and mec10 genes, mediate mechanotransduction in C. elegans touch neurons [60]. The deg/enac gene family has expanded extensively in the lineage leading to leech from the annelid ancestor; the Helobdella robusta genome contains 65 gene models labeled with the Pfam term 008585, corresponding 


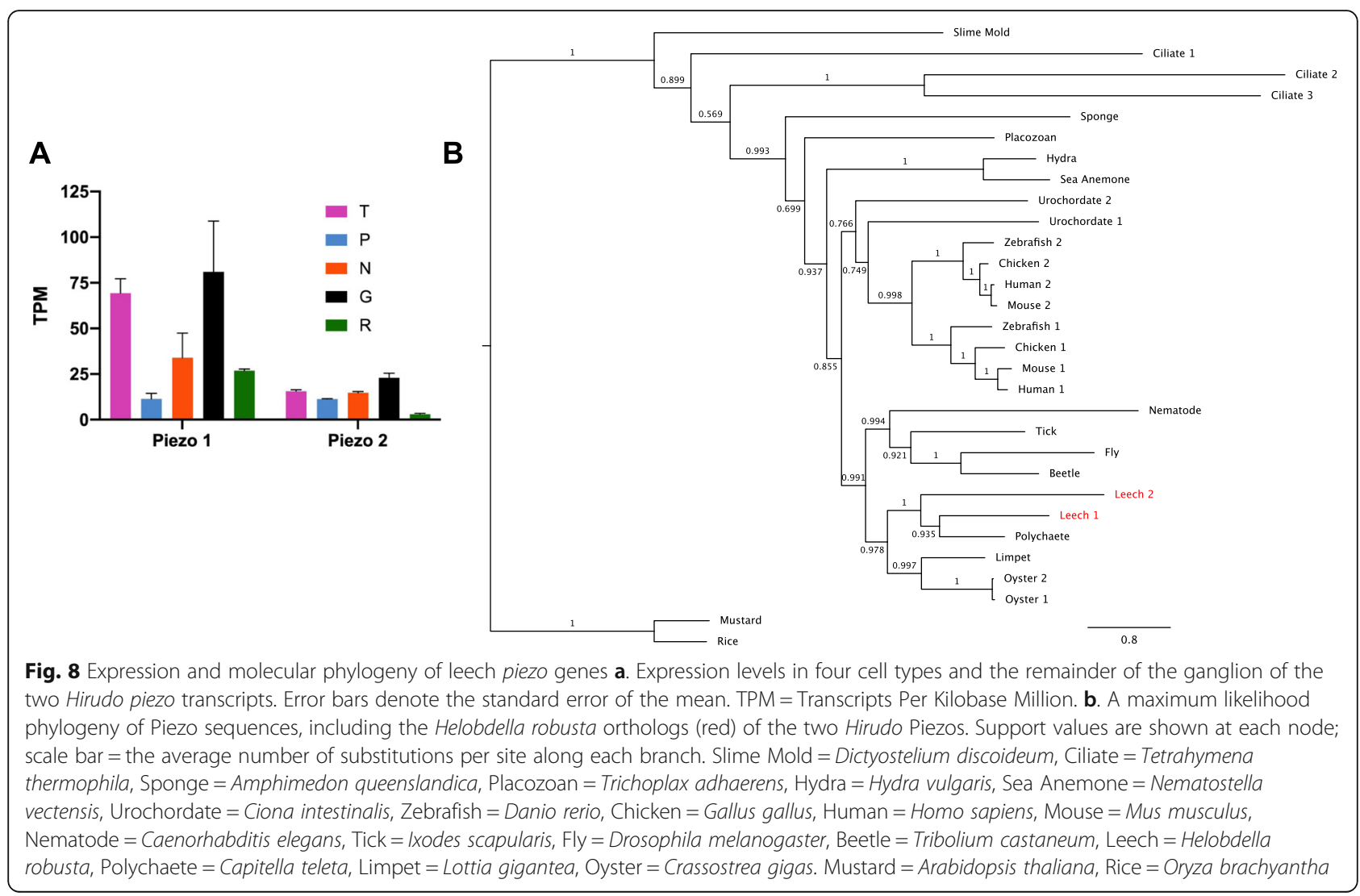

to ENaCs [61]. This expansion precludes us from identifying orthologs of mec4 and mec10 in leech. Our transcriptome of the Hirudo nervous system yielded at least 13 transcripts encoding putative $\mathrm{ENaCs}$, which BLAST to 9 presumptive orthologs in the Helobdella genome. Two of these Hirudo transcripts appear to be enriched in mechanosensory neurons; one (Hve-degenac1, corresponding to the Helobdella gene model 168363) shows moderate read counts (roughly 100 TPM) in the $\mathrm{N}$ cell sample and much lower counts (less than 25 TPM) in the other cell types and in the Gm samples. The other (Hve-degenac2, corresponding to the Helobdella gene model 185250) is expressed at much higher levels in both $\mathrm{P}$ and $\mathrm{N}$ cell samples (read counts of 1300 and 600 TPM, respectively, Fig. 10).

\section{Discussion}

Transcriptional profiles of individually identified, phenotypically distinct neurons

In the work presented here, we have used deep RNA sequencing on pools of individually dissected cells to generate extensive transcriptional profiles for four physiologically and functionally distinct classes of identified neurons from the leech Hirudo verbana, as well as for the overall ganglion. Pairwise comparisons between and among the datasets allowed us to generate lists of candidates for genes whose differential expression would contribute to the phenotypic differences among the extensively characterized touch $(\mathrm{T})$, pressure $(\mathrm{P})$, nociceptive $(\mathrm{N})$ and serotonergic neurosecretory Retzius (Rz) neurons of Hirudo; in situ hybridization (ISH) allowed us to validate the predicted gene expression patterns of selected genes.

The transcriptomes generated here also set the stage for fine-grained analysis of differences among neurons within these various classes, for example by scRNASeq comparisons of medial and lateral $\mathrm{N}$ and $\mathrm{P}$ neurons within ganglia, and of segment-specific differences in $\mathrm{Rz}$ neurons of reproductive segments M5 and M6, versus other midbody segments [22, 62].

\section{Expansion of the $h c n$ and ip3r gene families}

Comparative genomic studies indicate that the diversification of bilaterian taxa has been accompanied by lineage-specific expansions of various gene families. Leeches, for example, relative to an inferred annelid ancestor, appear to have undergone an expansion of the gene families encoding innexins, epithelial sodium channels $(\mathrm{ENaCs})$ and homeodomain-containing transcription factors [61, 63], and, as presented here, the hyperpolarization-activated, cyclic 

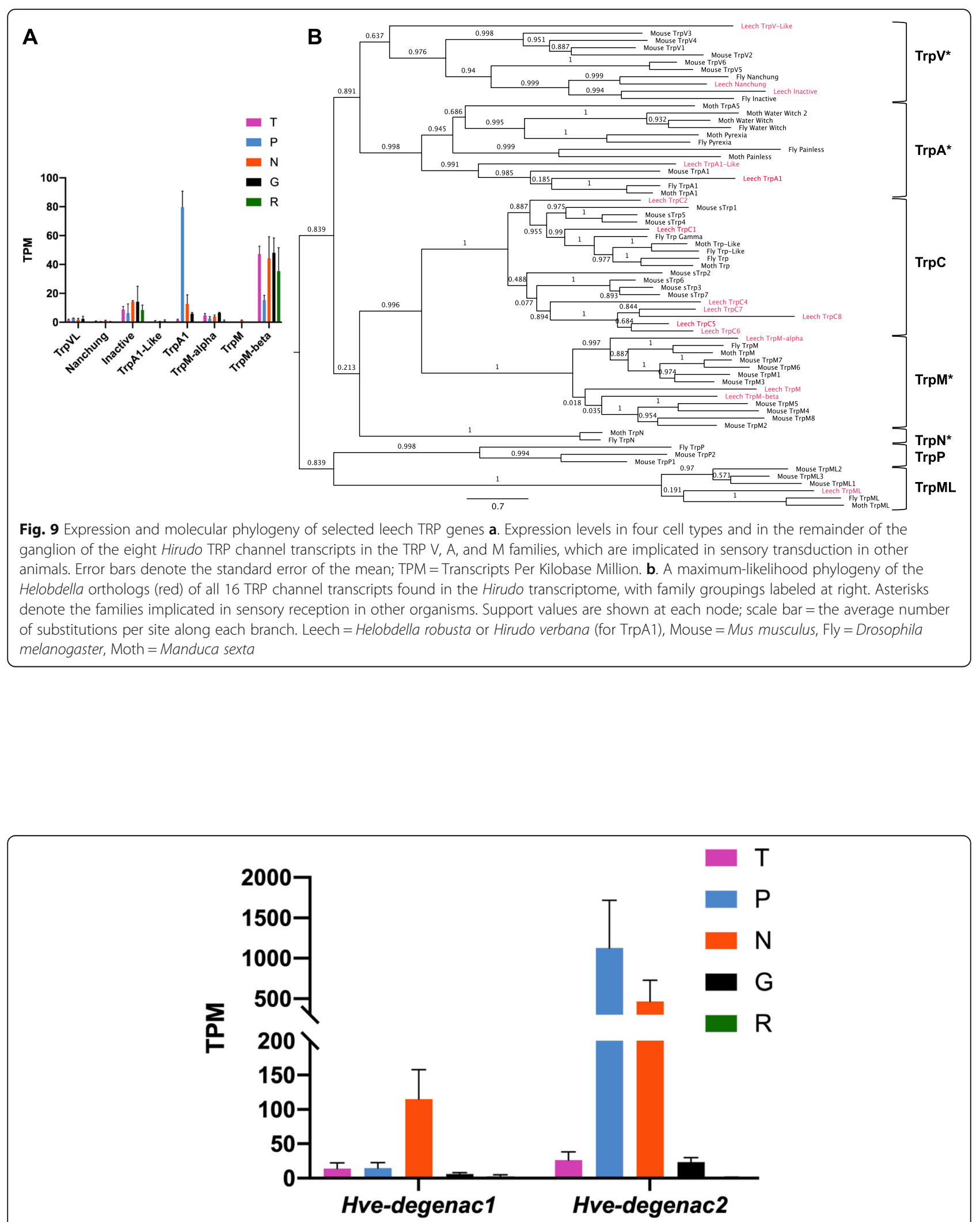

Fig. 10 Transcript abundances of differentially regulated Deg/ENaC genes in the Hirudo transcriptome. Colored bars denote expression levels in TPM (Transcripts Per Kilobase Million) for each cell type; error bars = the standard error of the mean. Hve-degenac1 = comp24767_c3, Hvedegenac2 $=$ comp19322_c0 
nucleotide-gated $(\mathrm{HCN})$ family of ion channels, within the super-family of cyclic nucleotide-gated (CNG) channels.

Finding that one of these $h c n$ genes, $h c n 4$, is expressed preferentially in $\mathrm{P}$ and $\mathrm{N}$ cells correlates with previous work showing that $\mathrm{P}$ and $\mathrm{N}$ cells exhibit enhanced sag voltages and shows how divergence in the regulation of expression among duplicated genes may contribute to divergence in cellular phenotypes. Moreover, this result enables biophysical studies to investigate the extent to which this expansion has been accompanied by functional divergence of the $\mathrm{HCN}$ channels.

A second instance of gene family expansion highlighted by this work is in the gene family encoding IP3 receptors (IP3Rs). In the IP3R gene family, three subtypes were inferred for the bilaterian ancestor: IP3RA, IP3RB and RyaR. The leech genome contains duplications of both IP3RA and IP3RB. We found that ip3rb2 is highly enriched in the $\mathrm{T}$ neurons (which respond to light touch) relative to any other cells in the ganglion. Molecular phylogenies indicate that the IP3RB sub-family of IP3 receptors was present in the bilaterian ancestor, but has been lost in the lineage leading to vertebrates. Accordingly, the physiological characterization of these receptors for the most part remain to be determined.

While physiological and pharmacological evidence shows that Rz neurons employ both IP3R- and RyaRmediated $\mathrm{Ca}^{+2}$ release [64, 65], we detect ip3ra and ip3rb but not ryar transcripts in this cell type. We posit that this is due to a difference in the limit of detection for expression of this transcript, possibly due to sequence artifacts introduced during the de novo transcriptome generation, as its expression levels are low in all of our samples (Fig. 5). In any case, this discrepancy highlights the need to complement bioinformatic analyses with direct experimentation.

Given that the $\mathrm{T}$ cells express both paralogs of the broadly conserved ip3ra sub-family in addition to $i p 3 r b 2$, we speculate that the broadly expressed IP3RAs carry out the housekeeping functions of $\mathrm{Ca}^{+2}$ homeostasis, and that the IP3RB family may have been co-opted evolutionarily for $\mathrm{T}$ cell-specific functions, the nature of which remain to be determined. We note that mechanical modulation of IP3R-dependent $\mathrm{Ca}^{+2}$ release has been observed in mouse endothelium [66].

\section{Identification of candidate mechanotransducer genes}

Transcriptional profiling allows us to sort through dozens of potential candidates and identify specific piezo, trp and deg/enac homologs as candidate transduction channels in leech mechanosensory neurons. We identify one of two piezo genes, two of $\sim 65 \mathrm{deg} / \mathrm{enac}$ genes, and one of at least 16 trp genes as prime transduction candidates in the three distinct classes of leech mechanosensory neurons. Moreover, these genes appear to be differentially expressed among the three classes of mechanosensory neurons, which correlates with their distinct physiological properties. Specifically, leech piezo1 appears to be up-regulated in the $\mathrm{T}$ neurons, which transduce light touch; this suggests a possible parallel with mammalian piezo, which functions to transduce touch in Merkel cells and the associated sensory neurons [51]. In contrast, the P neurons appear to upregulate the expression of leech $\operatorname{trp} A 1$ and one of the many leech deg/enac genes (Hve-degenac2, also increased in $\mathrm{N}$ cells), while a different deg/enac is differentially expressed in the $\mathrm{N}$ neurons (Hve-degenac1). Since $\mathrm{N}$ neurons function as multi-modal nociceptors, responding to salt, acid and heat, we anticipate that other receptors remain to be associated with this class of neurons.

Another intriguing possibility is that the genes that we identify in this study may interact with each other to transduce mechanical signals. For example, in several tissues in vertebrates, Trp channel activation can cause calcium release through IP3 receptors in the ER. While the Trp channels identified in vertebrates, such as TrpM7 [67] and Pkd2 [68], do not have exact orthologs in the leech, the fact that $\mathrm{T}$ cells differentially produce a noncanonical IP3 receptor (ip3rb2, Fig. 7) and express a member of the TrpM family (trpM-beta, Fig. 9) suggests that a similar mechanism may be at play in the lighttouch responsive neurons. Given the amenability of the leech for CRISPR/Cas9 and antisense knockdown techniques, we anticipate that future work will be able to test the functional roles of these candidates and other genes in manifesting the distinct phenotypes of the $\mathrm{T}, \mathrm{P}$ and $\mathrm{N}$ neurons.

\section{Similarities and differences between Hirudo and Helobdella}

Among leeches, the utility of hirudinid species (chiefly Hirudo verbana and $H$. medicinalis) as models for physiology and behavior is complemented by the utility of glossiphoniid species (e.g., Helobdella robusta and $H$. austinensis) as models for studying early development [69]. In addition to the advantages of being able to apply embryological approaches to the ontogeny of behavior, delineating the similarities and differences among different leech species provides an evolutionary perspective for within this taxon. Comparing the expression of orthologous genes in Helobdella and Hirudo revealed similarities in expression of Hau-hcn4, Hau-pcad1, Hau$d d c$ and Hau-tph, consistent with known similarities in ganglion architecture among leeches [44, 70-72].

One curious similarity between Hirudo and Helobdella is that in both species, the dopa decarboxylase ( $d d c$ ) gene that is enriched in serotonergic $\mathrm{Rz}$ neurons is not 
expressed in the smaller, dorsolateral and ventrolateral serotonergic neurons, while tryptophan hydroxylase $(t p h)$ is strongly expressed in all three serotonergic neurons in both species. It remains to be determined whether the decarboxylation step in serotonin biosynthesis is carried out by the product of one of the duplicated genes in the tyrosine decarboxylase clade of AADs in the lateral serotonergic neurons.

A noteworthy difference between the two species is that neither of the Helobdella orthologs of the $\mathrm{T}$ cell marker genes from Hirudo, encoding collagen-alpha and IP3 receptor type B, respectively showed the expected expression patterns in juvenile Helobdella. We speculate that the $\mathrm{T}$ neurons in the juvenile Helobdella used here had not yet differentiated to the point of expressing the collagen-alpha or ip3rb2 genes. An obvious experiment is to test for the expression of these genes in ganglia of adult Helobdella, but at present this experiment is technically challenging.

\section{Conclusions}

In conclusion, the work presented here provides comprehensive transcriptional profiles for four phenotypically distinct classes of identified neurons in the segmental nervous system of the leech Hirudo verbana, a tractable model for studying the neurobiological basis of behavior in terms of the properties and connections of individually identified cells. We have used ISH to show that candidate genes exhibit the predicted patterns of expression in Hirudo and that orthologous genes are similarly expressed in the nervous system of the leech Helobdella austinensis, a tractable model for studying annelid development at the cellular and molecular levels. This lays the basis for future work leveraging the strengths of each system and their underlying similarities to investigate the molecular processes underlying and linking mechanosensation, cell type specification, and behavior. Finally, investigating the differences between the species provides opportunities for studying the evolution of behavioral differences among species at the same level of cellular and molecular detail.

\section{Methods}

\section{Animals}

Hirudo verbana [73] were obtained from Leeches USA. Helobdella austinensis [74] were obtained from a laboratory breeding colony at UC Berkeley.

\section{Isolation of identified Mechanosensory neurons}

Visually identified T, P, N and Retzius neurons were isolated individually from the central nervous system of adult $H$. verbana as described previously $[75,76]$. In brief, leeches were anesthetized by immersion in ice, and short chains of midbody segmental ganglia (with the exception of ganglia 5 and 6) were dissected in Leech Ringer's solution [77] and pinned in a Sylgard-bottom dish. The ganglia were kept in L-15 culture medium (Gibco) supplemented with $6 \mathrm{mg} / \mathrm{ml}$ glucose, $0.1 \mathrm{mg} / \mathrm{ml}$ gentamycin (Sigma) and 2\% heat-inactivated fetal calf serum (FCS, Microlab). The capsule of each ganglion was opened to expose cell somata and the ganglia chains were incubated for $1 \mathrm{~h}$ in $2 \mathrm{mg} / \mathrm{ml}$ collagenase/dispase (Boehringer-Mannheim). After the enzyme treatment, Retzius, T, P and $\mathrm{N}$ neurons were identified visually by their size and location in the ganglion. Individual neurons were removed from the ganglia by suction using a fire-polished glass pipette. Isolated neurons were rinsed several times in L-15 to sterilize them and remove debris. Three groups of ten leeches were used, yielding three biological replicates, of $\sim 300$ cells each, for each cell type. Finally, ganglia from which all the mechanosensory and Retzius neurons had been removed were pooled to create three biological replicates to create the "ganglion" transcriptome.

\section{RNA extraction and sequencing}

RNA was isolated from pooled neurons that were stored at -80 in saline solution with $1 \%$ (v/v) Recombinant RNasin Ribonuclease Inhibitor (Promega). The RNA was extracted with the Quick-RNA micro prep kit (Zymo) and eluted in $7 \mu \mathrm{L}$ of nuclease-free water. The mRNA was isolated using the DynaBeads mRNA Purification kit (ThermoFisher) to select for poly-A RNA and libraries were constructed using the PrepX DNA Library kit (Takara). The resultant RNA libraries were sequenced by the Functional Genomics Library at UC Berkeley on an Illumina HiSeq 2500 with $2 \times 100$ bp reads.

\section{Transcriptome assembly and alignment}

We removed sequencing adapters and bases with low quality scores from the reads using the settings: ILLUMINACLIP:TruSeq3-PE.fa:2:30:10 LEADING:3 TRAILI NG:3 SLIDINGWINDOW:4:15 MINLEN:36. in Trimmomatic [78] and verified the quality post-trimming with FastQC. Overrepresented sequences in the data set post-processing were removed using custom IlluminaClip parameters in Trimmomatic. To facilitate de novo assembly of the transcripts, we performed k-mer normalization using the built-in kmer normalization script in Trinity [30]. In testing phases we also used khmer [79] with a cutoff value of 20 or 50 and a kmer value of 17 or 20 to compare alternative assembly methods. We then used Trinity [30] to create de novo transcriptomes using these normalized datasets and determined the most representative transcriptome of the datasets. The resultant transcriptome was annotated using BLASTX [80] against the full Helobdella robusta genomic protein model database [61] and the SWIS 
SProt Database [34]. The trimmed reads were then aligned to the transcriptome and the expression levels were determined using Kallisto [81].

\section{Expression analysis}

To identify genes that were differentially expressed among the five sample types, all ten possible pairwise comparisons were performed using the $\mathrm{R}$ package edge $\mathrm{R}$ [82] using a $p$-value of 0.01 after adjusting for multiple comparisons. All differentially regulated genes were then subjected to hierarchical clustering and grouped into 9 clusters using the cutree function and plotted using the $\mathrm{R}$ package dendextend [83]. A cutoff giving nine clusters was chosen because it was the smallest number of clusters that allowed for discrimination between all cell groups. Cluster-trait correlation analyses were performed using calculations from the R package WGCNA [84]. Plots were made using the $R$ packages gplots, ggplot2 [85], and reshape2 [86].

\section{In situ hybridization}

We dissected out ganglia from various midbody segments (M1 through M21, excluding the reproductive segments M5 and M6) of adult $H$. verbana on ice and pinned them onto small, Sylgard-coated plastic petri dishes in Leech Ringer's solution [77]. We then removed the proteinaceous outer sheath using a micro knife (Fine Science Tools) on the ventral face of the ganglion to expose the neuronal cell bodies. At this point, roughly trapezoidal wedges of sylgard to which one or more ganglia were pinned were cut from the dishes and transferred to $1.7 \mathrm{ml}$ polypropylene centrifuge tubes for all further processing. This step simplified the solution changes, reduced the volumes of solution required at each step, reduced damage to the ganglia, and prevented the nerves from folding over the ganglia during the final dehydration steps.

We then fixed the ganglia in $4 \%$ paraformaldehyde in $0.5 \mathrm{x}$ phosphate-buffered saline (PBS) for 2-3 h at room temperature. The ganglia were then brought through a methanol series (5 min at RT in 30, 50, 70, and $90 \%$ methanol), washed $3 \times 5 \mathrm{~min}$ in $100 \%$ methanol and stored overnight or until needed in $100 \%$ methanol at 4 degrees $C$, then rehydrated in a methanol series $(5 \mathrm{~min}$ at RT in 90, 70, 50, and 30\% methanol) and washed $2 \times$ $5 \mathrm{~min}$ at RT in PBS or PTw (PBS with $0.1 \%$ Tween 20). The samples were then digested with $20 \mu \mathrm{g} / \mathrm{mL}$ Proteinase $\mathrm{K}$ in PTw for 3-10 min at RT to allow for greater probe access. Digestion was stopped with one 30s wash followed by $2 \times 5 \mathrm{~min}$ washes in $2 \mathrm{mg} / \mathrm{mL}$ glycine in PBS. The ganglia were then washed $3 \times 5 \mathrm{~min}$ in $\mathrm{PBS}$ and post-fixed in $4 \%$ paraformaldehyde in PBS for 30-60 $\mathrm{min}$ at RT. The fixative was then removed with $2 \times 5 \mathrm{~min}$ washes in PTw.
To prepare for probe hybridization the ganglia were incubated for 5-10 min in a 1:1 solution of PTw and Hybridization buffer (Hyb: 50\% super pure formamide, 5X SSC, $0.2 \mathrm{mg} / \mathrm{mL}$ torula RNA, 1X Denhardt's solution, $0.1 \mathrm{mg} / \mathrm{mL}$ heparin, $0.1 \%$ Tween-20, $1 \mathrm{mg} / \mathrm{mL}$ CHAPS and $9.2 \mathrm{mMol}$ Citric Acid), followed by $5 \mathrm{~min}$ in Hyb at $\mathrm{RT}$ and then $3-16 \mathrm{~h}$ in fresh $\mathrm{Hyb}$ at $65^{\circ} \mathrm{C}$. For hybridization, the ganglia were covered with $500-750 \mu \mathrm{L}$ of Hyb containing $0.2-2.0 \mu \mathrm{g} / \mathrm{mL}$ riboprobe (denatured at $65{ }^{\circ} \mathrm{C}$ for $25 \mathrm{~min}$ prior to addition) and incubated in the probe solution for $16-48 \mathrm{~h}$ at $65^{\circ} \mathrm{C}$ in a rocking hybridization oven.

Probes were designed by using the IDT PrimerQuest tool to optimize for a PCR product of about 1000 nucleotides from the transcript of interest. Sequences of the primers used for probe synthesis can be found in Table S1. The PCR products were purified with the GeneJet Gel Extraction Kit (ThermoFisher) and then ligated into plasmids with the pGEM-T Easy Vector System (Promega). These plasmids were transformed into NEB 5alpha competent E. coli (New England Biolabs), amplified in Luria-Bertani broth cultures, purified from the cultures using the QIAprep Spin Miniprep Kit (Qiagen), and sequenced by the UC Berkeley DNA Sequencing Facility. Plasmids from positive clones were linearized by PCR or restriction digest, and riboprobes were synthesized with MEGAscript T7 and SP6 transcription kits (ThermoFisher) and Digoxigenin-11-UTP (SigmaAldrich).

To remove unbound probe, the samples were transferred to $2 \mathrm{X}$ SSC through a series of $5 \mathrm{~min}$ washes at $65^{\circ} \mathrm{C}$ (Hyb, 1:1 Hyb:SSC, SSC), followed by 20 min $0.2 \mathrm{X}$ $\mathrm{SSC}$ in PTw, $20 \mathrm{~min}$ 0.1X PTw and then $30 \mathrm{~s}$ and $5 \mathrm{~min}$ in PTw, all at RT. To reduce nonspecific antibody staining the ganglia were incubated with $1 \mathrm{X}$ Western Blocking Reagent (Roche) for $2-3 \mathrm{~h}$ at RT. The samples were then incubated in 1:4000 anti-Digoxigenin conjugated to Alkaline Phosphatase (Roche) in 1X Western Blocking solution for $18 \mathrm{~h}$ at $4{ }^{\circ} \mathrm{C}$ with rotation. The ganglia were rinsed $3 \times 30 \mathrm{~s}$ in PTw, followed by $5 \times 1$-h washes in PTw to remove excess antibody.

To visualize the antibody staining in the ganglia, PTw was replaced with BMPurple reagent (Sigma Aldrich) and incubated at RT in the dark until color was seen. The reaction was terminated by rinsing the samples in PTw $3 \times 5$ min followed by an hour-long incubation in PTw. The specimens were then cleared in a glycerol series (first $40-50 \%$ and then $80 \%$ ), after which they were unpinned from the sylgard block and mounted for microscopy.

\section{Dye tracing}

Individual ganglia were removed by dissection, pinned onto triangular-shaped slivers of Sylgard designed to slip 
into $1.5 \mathrm{ml}$ conical tubes, and then desheathed on the ventral or dorsal side. In some experiments, one or more $\mathrm{T}$ cells were injected with fixable fluorescent dye (Dextran, Texas Red 3000 MW Lysine; ThermoFisher; 50 mg/ $\mathrm{ml}$ in the electrode) by iontophoresis, alternating +5 and $-5 \mathrm{nA}$ pulses, each with a duration of $600 \mathrm{~ms}$. Injection times were typically on the order of $10-15 \mathrm{~min}$ total. Cells were fixed and processed for in situ hybridization as described above.

\section{Molecular Phylogenetics}

All protein sequences were obtained from the NCBI protein database [87], the $H$. robusta genome browser [88], the L. gigantea genome browser [89], or the C. teleta genome browser [90]. Protein alignments were generated via the phylogeny.fr website [91] using MUSCLE [92] and curated using Gblocks or Noisy curation alignment software [93, 94]. Finally, the maximum-likelihood phylogenies were generated with PhyML [95] using the LG substitution model and 100 replicates during any bootstrapping process. All sequences used in these analyses can be found in Supplementary File 6.

\section{Imaging}

Images in this manuscript were acquired with one of the following microscopes and configurations:

1) Leica MDG30 dissecting microscope with a Planapo 2X objective attached to a Leica DFC300 FX camera using Leica Application Suite version 4.3.0 for image acquisition. (Fig. 3a-d, f-h).

2) Zeiss Axiophot compound microscope outfitted with 5X Plan-Apochromat, NA 0.16; 10X Plan-Neofluar, NA 0.30; 20X Plan-Neofluar, NA 0.50; and 40X PlalnNeofluar, NA 0.75 objectives. Images were acquired with a Nikon CoolPix 5000 camera. (Fig. S3).

3) Nikon SMZ800 dissecting microscope with Plan 1X lens attached. Images acquired with a SPOT Insight QE Digital Camera Model 4.2 (Diagnostic Instruments). (Fig. 3e).

4) Nikon Eclipse Ti Inverted Scope using a Nikon Plan Fluor 10X / 0.30 Objective DIC L/N1. Images were acquired with a Hamamatsu Digital Camera C11440 ORCA Flash 2.8. (Fig. 4).

\footnotetext{
Abbreviations

CNS: Central nervous system; HCN: Hyperpolarization-activated cyclic nucleotide-gated; IP3R: Inositol triphosphate receptor; TRP: Transient receptor potential; scRNAseq: Single cell RNASeq; Rz: Retzius; Deg/ENaC: Degenerin/ epithelial sodium channel; Gm: Ganglion minus; ISH: In situ hybridization; TPM: Transcripts per million; TPH: Tryptophan hydroxylase; DDC: Dopa decarboxylase; Pcad: Protocadherin; AAD: Amino acid decarboxylase; AAAD: Aromatic amino acid decarboxylase; GAD: Glutamic acid decarboxylase; HD: Histamine decarboxylase; TD: Tyrosine decarboxylase; RyaR: Ryanodine receptor; BLAST: Basic local alignment search tool; PBS: Phosphate-buffered saline; PTw: PBS with 0.1\% tween; Hyb: Hybridization buffer; PCR: Polymerase chain reaction; SSC: Saline-sodium citrate
}

\section{Supplementary Information}

The online version contains supplementary material available at https://doi. org/10.1186/s12864-021-07526-0.

\section{Additional file 1. \\ Additional file 2. \\ Additional file 3. \\ Additional file 4. \\ Additional file $\mathbf{5}$. \\ Additional file 6 . \\ Additional file 7}

\section{Acknowledgements}

We thank Lidia Szczupak and Krista Todd for helpful comments and discussions.

\section{Authors' contributions}

$\mathrm{EH}-\mathrm{H}$ performed the RNASeq analysis, phylogenetic analyses, generated all figures, performed ISH experiments, and co-wrote the manuscript. SY performed ISH experiments. CW performed ISH experiments and assisted in writing the manuscript. MP submitted the original data to the sequencing facility and collected the initial raw data, in addition to performing initial analysis of the data. JA and VL performed dye tracing and ISH experiments. DB co-designed the study and assisted in data interpretation. FFD-M performed all cell dissections for the RNASeq experiments, co-designed the study, and assisted in writing the manuscript. DW co-designed the study, assisted in cell dissections and ISH experiments, and co-wrote the manuscript. The author (s) read and approved the final manuscript.

\section{Funding}

This work was supported by: University of California Institute for Mexico and the United States (Grant 2012 to D.A.W., D.B. and FFdM); the Human Frontier Science Program (grant RGP0060/2019 to D.A.W. and F.F.dM. and others), and the National Institutes of Health (NRSA F32NS095665 to E.H-H). This work used the UC Berkeley Functional Genomics lab for the library prep \& the UC Berkeley Vincent J. Coates Genomics Sequencing Laboratory for sequencing which are supported by NIH Instrumentation Grant S10 OD018174.

\section{Availability of data and materials}

The data underlying this article are available in the NCBI BioProject Database at https://www.ncbi.nlm.nih.gov/bioproject/, and can be accessed under the IDs PRJNA656790 and PRJNA686114.

\section{Declarations}

Ethics approval and consent to participate Not Applicable.

Consent for publication

Not Applicable.

Competing interests

The authors declare that they have no competing interests.

\section{Author details}

'Department of Molecular \& Cell Biology, University of California, Berkeley, Berkeley, CA, USA. ${ }^{2}$ Current address: Department of Integrative Biology, Michigan State University, East Lansing, MI, USA. ${ }^{3}$ Current address: Invitae Corporation, San Francisco, CA, USA. ${ }^{4}$ Department of Biology, Siena College, Loudonville, New York, NY, USA. Instituto de Fisiología Celular, Universidad Nacional Autónoma de México, Mexico City, Mexico. 
Received: 3 September 2020 Accepted: 11 March 2021

Published online: 25 March 2021

\section{References}

1. Shekhar K, Lapan SW, Whitney IE, Tran NM, Macosko EZ, Kowalczyk M, et al. Comprehensive classification of retinal bipolar neurons by single-cell transcriptomics. Cell. 2016;166(5):1308-1323.e30.

2. Diamond JS. Inhibitory interneurons in the retina: types, circuitry, and function. Annu Rev Vis Sci. 2017;3:1-24.

3. Laboissonniere LA, Sonoda T, Lee SK, Trimarchi JM, Schmidt TM. Single-cell RNA-Seq of defined subsets of retinal ganglion cells. JoVE J Vis Exp. 2017; 123:e55229.

4. Waylen LN, Nim HT, Martelotto LG, Ramialison M. From whole-mount to single-cell spatial assessment of gene expression in 3D. Commun Biol. 2020; 3(1):1-11.

5. Sattelle DB, Buckingham SD. Invertebrate studies and their ongoing contributions to neuroscience. Invertebr Neurosci IN. 2006;6(1):1-3. https:// doi.org/10.1007/s10158-005-0014-7.

6. Selverston Al. Invertebrate central pattern generator circuits. Philos Trans R Soc B Biol Sci. 2010;365(1551):2329-45. https://doi.org/10.1098/rstb.2009.02 70.

7. Taghert PH, Nitabach MN. Peptide neuromodulation in invertebrate model systems. Neuron. 2012;76(1):82-97. https://doi.org/10.1016/j.neuron.2012.08. 035.

8. Katz PS, Quinlan PD. The importance of identified neurons in gastropod molluscs to neuroscience. Curr Opin Neurobiol. 2019;56:1-7. https://doi. org/10.1016/j.conb.2018.10.009.

9. Retzius G. Zur Kenntniss des centralen Nervensystems der Würmer. In: Biologische Untersuchungen, Neue Folge II. Stockholm: Samson \& Wallin; 1891. p. 1-28

10. Kristan WB, Calabrese RL, Friesen WO. Neuronal control of leech behavior. Prog Neurobiol. 2005;76(5):279-327. https://doi.org/10.1016/j.pneurobio.2 005.09.004.

11. Weisblat DA. Asymmetric cell divisions in the early embryo of the leech Helobdella robusta. In: Macieira-Coelho A, editor. Asymmetric cell division [internet]. Berlin, Heidelberg: Springer; 2007. p. 79-95. [cited 2020 Jul 21] (Progress in molecular and subcellular biology). Available from: 2007. https://doi.org/https://doi.org/10.1007/978-3-540-69161-7_4

12. Mladinic M, Muller KJ, Nicholls JG. Central nervous system regeneration: from leech to opossum: central nervous system regeneration. J Physiol. 2009;587(12):2775-82. https://doi.org/10.1113/jphysiol.2009.169938.

13. Wagenaar DA. A classic model animal in the 21st century: recent lessons from the leech nervous system. J Exp Biol. 2015;218(21):3353-9. https://doi. org/10.1242/jeb.113860.

14. Del-Bel E, De-Miguel FF. Extrasynaptic neurotransmission mediated by exocytosis and diffusive release of transmitter substances. Front Synaptic Neurosci. 2018;10 [cited 2020 Jun 20] Available from: https://www.ncbi.nlm. nih.gov/pmc/articles/PMC6003215/.

15. Kuo D-H, Lai Y-T. On the origin of leeches by evolution of development. Develop Growth Differ. 2019;61(1):43-57. https://doi.org/10.1111/dgd.12573.

16. Nicholls JG, Baylor DA. Specific modalities and receptive fields of sensory neurons in CNS of the leech. J Neurophysiol. 1968;31(5):740-56. https://doi. org/10.1152/jn.1968.31.5.740.

17. Blackshaw SE. Morphology and distribution of touch cell terminals in the skin of the leech. J Physiol. 1981;320(1):219-28. https://doi.org/10.1113/ jphysiol.1981.sp013945

18. Gerard E, Hochstrate P, Dierkes P-W, Coulon P. Functional properties and cell type specific distribution of th channels in leech neurons. J Exp Biol. 2012;215(2):227-38. https://doi.org/10.1242/jeb.062836.

19. Lockery SR, Sejnowski TJ. Distributed processing of sensory information in the leech. III. A dynamical neural network model of the local bending reflex. J Neurosci. 1992;12(10):3877-95. https://doi.org/10.1523/JNEUROSCI.12-10-03 877.1992.

20. Lewis JE, Kristan WB. A neuronal network for computing population vectors in the leech. Nature. 1998;391(6662):76-9. https://doi.org/10.1038/34172.

21. Kretzberg J, Pirschel F, Fathiazar E, Hilgen G. Encoding of tactile stimuli by mechanoreceptors and interneurons of the medicinal leech. Front Physiol. 2016;7:506.

22. Pastor J, Soria B, Belmonte C. Properties of the nociceptive neurons of the leech segmental ganglion. J Neurophysiol. 1996;75(6):2268-79. https://doi. org/10.1152/jn.1996.75.6.2268
23. Hagiwara S, Morita $\mathrm{H}$. Electrotonic transmission between two nerve cells in leech ganglion. J Neurophysiol. 1962;25(6):721-31. https://doi.org/10.1152/ jn.1962.25.6.721.

24. Rude S, Coggeshall E, Van Orden LS. Chemical and ultrastructural identification of 5-hydroxytryptamine in an identified neuron. J Cell Biol. 1969:41(3):832-54. https://doi.org/10.1083/jcb.41.3.832.

25. Beck A, Lohr C, Nett W, Deitmer JW. Bursting activity in leech Retzius neurons induced by low external chloride. Pflugers Arch. 2001;442(2):26372. https://doi.org/10.1007/s004240100525.

26. De-Miguel FF, Leon-Pinzon C, Noguez P, Mendez B. Serotonin release from the neuronal cell body and its long-lasting effects on the nervous system. Philos Trans R Soc B Biol Sci. 2015;370(1672):20140196. https://doi.org/10.1 098/rstb.2014.0196.

27. Chiquet M, Nicholls JG. Neurite outgrowth and synapse formation by identified leech neurones in culture. J Exp Biol. 1987;132(1):191-206.

28. Nicholls JG, Hernandez UG. Growth and synapse formation by identified leech Neurones in culture: a review. Q J Exp Physiol. 1989;74(6):965-73. https://doi.org/10.1113/expphysiol.1989.sp003372.

29. Hubert M, Rousseeuw PJ, Branden KV. ROBPCA: a new approach to robust principal component analysis. Technometrics. 2005;47(1):64-79. https://doi. org/10.1198/004017004000000563.

30. Grabherr MG, Haas BJ, Yassour M, Levin JZ, Thompson DA, Amit I, Adiconis X, Fan L, Raychowdhury R, Zeng Q, Chen Z, Mauceli E, Hacohen N, Gnirke A, Rhind N, di Palma F, Birren BW, Nusbaum C, Lindblad-Toh K, Friedman N, Regev A. Trinity: reconstructing a full-length transcriptome without a genome from RNA-Seq data. Nat Biotechnol. 2011;29(7):644-52. https://doi. org/10.1038/nbt.1883.

31. Wagner GP, Kin K, Lynch VJ. Measurement of mRNA abundance using RNAseq data: RPKM measure is inconsistent among samples. Theory Biosci Theor Den Biowissenschaften. 2012;131(4):281-5. https://doi.org/10.1007/s12 064-012-0162-3.

32. Babenko W, Podgorny OV, Manuvera VA, Kasianov AS, Manolov Al, Grafskaia EN, Shirokov DA, Kurdyumov AS, Vinogradov DV, Nikitina AS, Kovalchuk SI, Anikanov NA, Butenko IO, Pobeguts OV, Matyushkina DS, Rakitina DV, Kostryukova ES, Zgoda VG, Baskova IP, Trukhan VM, Gelfand MS, Govorun VM, Schiöth HB, Lazarev VN. Draft genome sequences of Hirudo medicinalis and salivary transcriptome of three closely related medicinal leeches. BMC Genomics. 2020;21(1):331. https://doi.org/10.1186/s12864-020-6748-0.

33. Kvist S, Manzano-Marín A, de Carle D, Trontelj P, Siddall ME. Draft genome of the European medicinal leech Hirudo medicinalis (Annelida, Clitellata, Hirudiniformes) with emphasis on anticoagulants. Sci Rep. 2020 Jun 18; 10(1):9885. https://doi.org/10.1038/s41598-020-66749-5.

34. The UniProt Consortium. UniProt: a worldwide hub of protein knowledge. Nucleic Acids Res. 2019;47(D1):D506-15. https://doi.org/10.1093/nar/gky1049.

35. Belanger JH, Orchard I. Leydig cells: octopaminergic neurons in the leech. Brain Res. 1986 Sep 24;382(2):387-91. https://doi.org/10.1016/0006-8993 (86)91349-1.

36. Coggeshall RE, Fawcett DW. The fine structure of the central nervous system of the leech, Hirudo Medicinalis. J Neurophysiol. 1964;27:229-89.

37. Fuchs PA, Nicholls JG, Ready DF. Membrane properties and selective connexions of identified leech neurones in culture. J Physiol. 1981;316(1): 203-23. https://doi.org/10.1113/jphysiol.1981.sp013783.

38. Dykes IM, Freeman FM, Bacon JP, Davies JA. Molecular basis of gap junctional communication in the CNS of the leech Hirudo medicinalis. J Neurosci. 2004; 24(4):886-94. https://doi.org/10.1523/JNEUROSCl.3676-03.2004.

39. Henderson LP. The role of 5-hydroxytryptamine as a transmitter between identified leech neurones in culture. J Physiol. 1983;339(1):309-24. https:// doi.org/10.1113/jphysiol.1983.sp014718.

40. Nusbaum MP, Kristan WB. Swim initiation in the leech by serotonincontaining interneurones, cells 21 and 61. J Exp Biol. 1986;122:277-302.

41. Stuart DK, Blair SS, Weisblat DA. Cell lineage, cell death, and the developmental origin of identified serotonin- and dopamine-containing neurons in the leech. J Neurosci. 1987;7(4):1107-22. https://doi.org/10.1523/ JNEUROSCI.07-04-01107.1987.

42. Scholnick SB, Bray SJ, Morgan BA, McCormick CA, Hirsh J. CNS and hypoderm regulatory elements of the Drosophila melanogaster dopa decarboxylase gene. Science. 1986;234(4779):998-1002. https://doi.org/1 $0.1126 /$ science.3095924.

43. Juorio AV, Li XM, Walz W, Paterson IA. Decarboxylation of L-dopa by cultured mouse astrocytes. Brain Res. 1993;626(1-2):306-9. https://doi.org/1 0.1016/0006-8993(93)90592-B. 
44. Baltzley MJ, Gaudry Q, Kristan WB. Species-specific behavioral patterns correlate with differences in synaptic connections between homologous mechanosensory neurons. J Comp Physiol A. 2010;196(3):181-97. https://doi. org/10.1007/s00359-010-0503-y.

45. Angstadt JD, Calabrese RL. A hyperpolarization-activated inward current in heart interneurons of the medicinal leech. J Neurosci. 1989;9(8):2846-57. https://doi.org/10.1523/JNEUROSCI.09-08-02846.1989.

46. Angstadt JD. Persistent inward currents in cultured Retzius cells of the medicinal leech. J Comp Physiol A. 1999;184(1):49-61. https://doi.org/10.1 007/s003590050305

47. Northcutt AJ, Fischer EK, Puhl JG, Mesce KA, Schulz DJ. An annotated CNS transcriptome of the medicinal leech, Hirudo verbana: De novo sequencing to characterize genes associated with nervous system activity. PLoS One. 2018;13(7):e0201206. https://doi.org/10.1371/journal.pone.0201206.

48. Parys JB, Vervliet T. New insights in the IP3 receptor and its regulation. Adv Exp Med Biol. 2020;1131:243-70. https://doi.org/10.1007/978-3-030-124 57-1_10.

49. Alzayady KJ, Sebé-Pedrós A, Chandrasekhar R, Wang L, Ruiz-Trillo I, Yule DI. Tracing the evolutionary history of inositol, 1, 4, 5-Trisphosphate receptor: insights from analyses of Capsaspora owczarzaki Ca2+ Release Channel Orthologs. Mol Biol Evol. 2015;32(9):2236-53. https://doi.org/10.1093/ molbev/msv098.

50. Wu J, Lewis A, Grandl J. Touch, tension, and transduction - the function and regulation of Piezo ion channels. Trends Biochem Sci. 2017;42(1):57-71. https://doi.org/10.1016/j.tibs.2016.09.004.

51. Woo S-H, Ranade S, Weyer AD, Dubin AE, Baba Y, Qiu Z, Petrus M, Miyamoto T, Reddy K, Lumpkin EA, Stucky CL, Patapoutian A. Piezo2 is required for Merkel-cell mechanotransduction. Nature. 2014;509(7502):622-6. https://doi.org/10.1038/nature13251.

52. Kim SE, Coste B, Chadha A, Cook B, Patapoutian A. The role of Drosophila Piezo in mechanical nociception. Nature. 2012;483(7388):209-12. https://doi. org/10.1038/nature10801.

53. Murthy SE, Dubin AE, Patapoutian A. Piezos thrive under pressure: mechanically activated ion channels in health and disease. Nat Rev Mol Cell Biol. 2017;18(12):771-83. https://doi.org/10.1038/nrm.2017.92.

54. Clapham DE. TRP channels as cellular sensors. Nature. 2003;426(6966):51724. https://doi.org/10.1038/nature02196.

55. Nilius B, Owsianik G. The transient receptor potential family of ion channels. Genome Biol. 2011;12(3):218. https://doi.org/10.1186/gb-2011-12-3-218.

56. Gees M, Owsianik G, Nilius B, Voets T. TRP channels. Compr Physiol. 2012; 2(1):563-608. https://doi.org/10.1002/cphy.c110026.

57. Julius D. TRP channels and pain. Annu Rev Cell Dev Biol. 2013;29(1):355-84. https://doi.org/10.1146/annurev-cellbio-101011-155833.

58. Peng G, Shi X, Kadowaki T. Evolution of TRP channels inferred by their classification in diverse animal species. Mol Phylogenet Evol. 2015;84:14557. https://doi.org/10.1016/j.ympev.2014.06.016.

59. Schüler A, Schmitz G, Reft A, Özbek S, Thurm U, Bornberg-Bauer E. The rise and fall of TRP-N, an ancient family of Mechanogated ion channels, in Metazoa. Genome Biol Evol. 2015;7(6):1713-27. https://doi.org/10.1093/gbe/ evv091.

60. Geffeney SL, Goodman MB. How we feel: ion channel partnerships that detect mechanical inputs and give rise to touch and pain perception. Neuron. 2012;74(4):609-19. https://doi.org/10.1016/j.neuron.2012.04.023.

61. Simakov O, Marletaz F, Cho S-J, Edsinger-Gonzales E, Havlak P, Hellsten U, Kuo DH, Larsson T, Lv J, Arendt D, Savage R, Osoegawa K, de Jong P, Grimwood J, Chapman JA, Shapiro H, Aerts A, Otillar RP, Terry AY, Boore JL, Grigoriev IV, Lindberg DR, Seaver EC, Weisblat DA, Putnam NH, Rokhsar DS. Insights into bilaterian evolution from three spiralian genomes. Nature. 2013;493(7433):526-31. https://doi.org/10.1038/nature11696.

62. Loer C, Jellies J, Kristan W. Segment-specific morphogenesis of leech Retzius neurons requires particular peripheral targets. J Neurosci. 1987;7(9):2630-8. https://doi.org/10.1523/JNEUROSCI.07-09-02630.1987.

63. Kandarian B, Sethi J, Wu A, Baker M, Yazdani N, Kym E, Sanchez A, Edsall L, Gaasterland T, Macagno E. The medicinal leech genome encodes 21 innexin genes: different combinations are expressed by identified central neurons. Dev Genes Evol. 2012;222(1):29-44. https://doi.org/10.1007/s00427011-0387-z.

64. Trueta C, Sánchez-Armass S, Morales MA, De-Miguel FF. Calcium-induced calcium release contributes to somatic secretion of serotonin in leech Retzius neurons. J Neurobiol. 2004;61(3):309-16. https://doi.org/10.1002/ neu.20055.
65. Leon-Pinzon C, Cercós MG, Noguez P, Trueta C, De-Miguel FF. Exocytosis of serotonin from the neuronal soma is sustained by a serotonin and calciumdependent feedback loop. Front Cell Neurosci. 2014;8. [cited 2020 Aug 12] Available from: https://www.frontiersin.org/articles/https://doi.org/10.3389/ fncel.2014.00169/full

66. Wilson C, Saunter CD, Girkin JM, McCarron JG. Pressure-dependent regulation of $\mathrm{Ca} 2+$ signalling in the vascular endothelium. J Physiol. 2015; 593(24):5231-53. https://doi.org/10.1113/JP271157.

67. Xiao E, Chen C, Zhang Y. The mechanosensor of mesenchymal stem cells: mechanosensitive channel or cytoskeleton? Stem Cell Res Ther. 2016;7 [cited 2020 Aug 12] Available from: https://www.ncbi.n/m.nih.gov/pmc/a rticles/PMC5029093/.

68. Delmas P. Polycystins: from Mechanosensation to gene regulation. Cell. 2004;118(2):145-8. https://doi.org/10.1016/j.cell.2004.07.007.

69. Kutschera U, Weisblat DA. Leeches of the genus Helobdella as model organisms for Evo-Devo studies. Theory Biosci Theor Den Biowissenschaften. 2015;134(3-4):93-104. https://doi.org/10.1007/s12064-015-0216-4.

70. Macagno ER. Number and distribution of neurons in leech segmental ganglia. J Comp Neurol. 1980 Mar 15;190(2):283-302. https://doi.org/10.1 002/cne.901900206.

71. Kramer AP, Kuwada JY. Formation of the receptive fields of leech mechanosensory neurons during embryonic development. J Neurosci. 1983; 3(12):2474-86. https://doi.org/10.1523/JNEUROSCI.03-12-02474.1983.

72. Kramer AP, Weisblat DA. Developmental neural kinship groups in the leech. J Neurosci. 1985;5(2):388-407. https://doi.org/10.1523/JNEUROSCI.05-02-003 88.1985.

73. Siddall ME, Trontelj P, Utevsky SY, Nkamany M, Macdonald KS. Diverse molecular data demonstrate that commercially available medicinal leeches are not Hirudo medicinalis. Proc Biol Sci. 2007;274(1617):1481-7.

74. Kutschera U, Langguth $\mathrm{H}, \mathrm{Kuo}$ D-H, Weisblat DA, Shankland M. Description of a new leech species from North America, Helobdella austinensis n. sp. (Hirudinea: Glossiphoniidae), with observations on its feeding behaviour. Zoosystematics Evol. 2013;89(2):239-46. https://doi.org/10.1002/zoos.2013 00010.

75. Dietzel ID, Drapeau P, Nicholls JG. Voltage dependence of 5hydroxytryptamine release at a synapse between identified leech neurones in culture. J Physiol. 1986;372(1):191-205. https://doi.org/10.1113/jphysiol.1 986.sp016004.

76. De-Miguel FE, Vargas J. Different determinants on growth and synapse formation in cultured neurons. Neuroreport. 1997:8(3):761-5. https://doi. org/10.1097/00001756-199702100-00036.

77. Muller KJ, Scott SA. Transmission at a 'direct' electrical connexion mediated by an interneurone in the leech. J Physiol. 1981;311(1):565-83. https://doi. org/10.1113/jphysiol.1981.sp013605.

78. Bolger AM, Lohse M, Usadel B. Trimmomatic: a flexible trimmer for Illumina sequence data. Bioinformatics. 2014;30(15):2114-20. https://doi.org/10.1093/ bioinformatics/btu170.

79. Crusoe MR, Alameldin HF, Awad S, Boucher E, Caldwell A, Cartwright R, et al. The khmer software package: enabling efficient nucleotide sequence analysis. F1000Research. 2015:4:900

80. Altschul SF, Gish W, Miller W, Myers EW, Lipman DJ. Basic local alignment search tool. J Mol Biol. 1990;215(3):403-10. https://doi.org/10.1016/S0022-2 836(05)80360-2.

81. Bray NL, Pimentel H, Melsted P, Pachter L. Near-optimal probabilistic RNAseq quantification. Nat Biotechnol. 2016;34(5):525-7. https://doi.org/10.1038/ nbt.3519.

82. Robinson MD, McCarthy DJ, Smyth GK. edgeR: a Bioconductor package for differential expression analysis of digital gene expression data. Bioinformatics. 2010;26(1):139-40. https://doi.org/10.1093/bioinformatics/ btp616.

83. Galili T. Dendextend: an R package for visualizing, adjusting and comparing trees of hierarchical clustering. Bioinforma Oxf Engl. 2015;31(22):3718-20. https://doi.org/10.1093/bioinformatics/btv428.

84. Langfelder P, Horvath S. WGCNA: an R package for weighted correlation network analysis. BMC Bioinformatics. 2008;9(1):559. https://doi.org/10.11 86/1471-2105-9-559.

85. Wickham H. Ggplot2: Elegant Graphics for Data Analysis [Internet]. 2nd ed. Switzerland: Springer International Publishing; 2016. [cited 2020 Jul 21]. (Use R!). Available from: https://www.springer.com/gp/book/9783319242750

86. Wickham H. Reshaping data with the reshape package. J Stat Softw. 2007; 21(1):1-20. 
87. Protein [Internet]. Bethesda (MD): National Library of Medicine (US), National Center for Biotechnology Information; 2004. [cited 2021 Mar 16]. Available from: https://www.ncbi.nlm.nih.gov/protein/.

88. The JGI Helobdella robusta Genome Browser. https://mycocosm.jgi.doe.gov/ Helro1/Helro1.home.html. Accessed Dec 2020.

89. The JGI Lottia gigantea Genome Browser. https://mycocosm.jgi.doe.gov/ Lotgi1/Lotgi1.home.html. Accessed Dec 2020.

90. The JGI Capitella teleta Genome Browser. https://mycocosm.jgi.doe.gov/Ca pca1/Capca1.home.htmlhttps://mycocosm.jgi.doe.gov/Capca1/Capca1.home. html. Accessed Dec 2020.

91. Dereeper A, Guignon V, Blanc G, Audic S, Buffet S, Chevenet F, et al. Phylogeny.fr: robust phylogenetic analysis for the non-specialist. Nucleic Acids Res. 2008;36(Web Server issue):W465-9.

92. Edgar RC. MUSCLE: multiple sequence alignment with high accuracy and high throughput. Nucleic Acids Res. 2004;32(5):1792-7. https://doi.org/10.1 093/nar/gkh340.

93. Castresana J. Selection of conserved blocks from multiple alignments for their use in phylogenetic analysis. Mol Biol Evol. 2000;17(4):540-52. https:// doi.org/10.1093/oxfordjournals.molbev.a026334.

94. Dress AW, Flamm C, Fritzsch G, Grünewald S, Kruspe M, Prohaska SJ, et al. Noisy: identification of problematic columns in multiple sequence alignments. Algorithms Mol Biol AMB. 2008;3(1):7. https://doi.org/10.1186/1 748-7188-3-7.

95. Guindon S, Dufayard J-F, Lefort V, Anisimova M, Hordijk W, Gascuel O. New algorithms and methods to estimate maximum-likelihood phylogenies: assessing the performance of PhyML 3.0. Syst Biol. 2010 May 1;59(3):307-21. https://doi.org/10.1093/sysbio/syq010.

\section{Publisher's Note}

Springer Nature remains neutral with regard to jurisdictional claims in published maps and institutional affiliations.

Ready to submit your research? Choose BMC and benefit from:

- fast, convenient online submission

- thorough peer review by experienced researchers in your field

- rapid publication on acceptance

- support for research data, including large and complex data types

- gold Open Access which fosters wider collaboration and increased citations

- maximum visibility for your research: over $100 \mathrm{M}$ website views per year

At $\mathrm{BMC}$, research is always in progress.

Learn more biomedcentral.com/submissions 